\title{
MONSOON MISSION A Targeted Activity to Improve Monsoon Prediction across Scales
}

Suryachandra A. Rao, B. N. Goswami, A. K. Sahal, E. N. Rajagopal, P. Mukhopadhyay, M. Rajeevan, S. Nayak, L. S. Rathore, S. S. C., Sheno, K. J. Ramesh, R. S. Nanjundiah, M. Ravichandran, A. K. Mitra, D. S. Pal, S. K. R. Bhowmik, A. Hazra, S. Mahapatra, S. K. Saha, H. S. Chaudhari, S. Joseph, P. Sreenivas, S. Pokhrel, P. A. Pillai, R. Chattopadhyay, M. Deshpande, R. P. M. Krishna, Renu S. Das, V. S. Prasad, S. Abhilash, S. Panickal, R. Krishnan, S. Kumar, D. A. Ramu, S. S. Reddy, A. Arora, T. Goswami, A. Ral, A. Srivastava, M. Pradhan, S. Tirkey, M. Ganal, R. Mandal, A. Dey, S. Sarkar, S. Malviya, A. Dhakate, K. Salunke, and Parvinder Maini

The Monsoon Mission is a national program that has nurtured a system to provide skillful Indian summer monsoon predictions, benefiting society and advancing global science.

$\mathrm{T}$ he skill of seasonal predictions of Indian summer monsoon rainfall (ISMR) by climate models remained "low" (correlation value $R$ between observation and predictions of about 0.4 ; Rajeevan et al. 2012), significantly below the estimates of potential predictability limit (PPL 0.65; Kumar et al. 2005; Kang and Shukla 2006) for seasonal mean monsoon forecasts one season in advance. Unfortunately, despite the improved simulation of other global climate modes in coupled general circulation models (GCMs), the simulation of major modes of monsoon variability remained problematic (Kim et al. 2012; Sperber et al. 2013; Sabeerali et al. 2013; Shashikanth et al. 2014; Ramesh and Goswami 2015; Alessandri et al. 2015; Johnson et al. 2017; Annamalai et al. 2017; Mishra et al. 2018), calling for targeted model developments to address the generic biases in simulating the Indian monsoon system. Although the India Meteorological Department (IMD) has considerable experience in predicting the ISMR using statistical models, with moderate success, the limitations of these models have been recognized (Gadgil et al. 2005; DelSole and Shukla 2009). Until 2009, IMD had been issuing short-range forecasts using regional models, while the medium-range forecasts were issued based on a low-resolution global NWP model (atmospheric GCMs) being run by National Centre for Medium Range Weather Forecasting (NCMRWF). Operational dynamical system for extended-range prediction did not exist. The foundation for the Monsoon Mission (MM) was put in place well before the official sanction in 2012. The operational requirement of day-today weather forecasts at short- to medium-range time scales was being met through other non-Indian operational centers (monsoon reports, available online at www.imd.gov.in/pages/monsoon_main.php). Lack of adequate high-performance computing facilities in the country held back the seasonal and extendedrange prediction using coupled climate models and high-resolution weather prediction.

Against this backdrop, the Ministry of Earth Sciences (MoES), Government of India, launched the Monsoon Mission in 2012. This mission mode program aimed not only to implement 1) a state-ofthe-art dynamical seasonal prediction system, 2) dynamical extended-range prediction system for active and break spells, and 3) ensemble short-range weather prediction system using a high-resolution global 
atmospheric model, but also to carry out the fundamental and applied research and development (R\&D) required to improve the models' depiction and skill of the Indian monsoon. The first phase of the MM ended in 2017. It is important to keep in mind that, unlike in research projects, the objective of a mission mode program is the demonstration of the potential for improvement in skill. Hence, the deliverable of a mission mode program must be a demonstration of improvement in skill. Further, all the research work must be on the Operational Modeling Framework so that the research can be seamlessly transferred to the operational model. This article describes the scientific basis for the program, its implementation strategy, and its demonstrable success. With proper planning and financial support from the MoES, active cooperation between several institutes within the ministry, and input from national and international community in $\mathrm{R} \& \mathrm{D}$, the targeted objectives of the programs were achieved, making Indian weather and climate prediction systems competitive. It is also

affiliations: Rao, Sahal, Mukhopadhyay, Hazra, Mahapatra, Saha, Chaudhari, Joseph, Pentakota, Pokhrel, Pillal, Chattopadhyay, Deshrande, Krishna, Das, Panickal, Krishnan, Kumar, Ramu, Arora, Goswami, Rai, Srivastava, Pradhan, Tirkey, Ganal, Mandal, Dey, Sarkar, Malviya, Dhakate, and SALUNKE-Indian Institute of Tropical Meteorology, Pashan, Pune, India; GoswaMI-Cotton University, Guwahati, Assam, India; Rajagopal, Mitra, and Prasad-National Center for Medium Range Weather Forecasting, Noida, Uttar Pradesh, India; ABHILASH-Department of Atmospheric Sciences, Cochin University of Science and Technology, Cochin, India; RajeEVAN AND MAINI-Ministry of Earth Sciences, Government of India, New Delhi, India; NAYAK—National Institute of Advanced Studies, Bengaluru, India; Rathore, Ramesh, Pal, AND BhowmikIndia Meteorological Department, Government of India, New Delhi, India; ShenOI AND RedDY-Indian National Centre for Ocean Information Services, Hyderabad, India; NANJUNDIAHIndian Institute of Tropical Meteorology, Pashan, Pune, and Centre for Atmospheric and Oceanic Sciences, Indian Institute of Science, Bangalore, India; RAVICHANDRAN-National Centre for Polar and Ocean Research, Goa, India

CORRESPONDING AUTHOR: Suryachandra A. Rao, surya@tropmet.res.in

The abstract for this article can be found in this issue, following the table of contents.

DOI:I0.II75/BAMS-D-17-0330.I

In final form 28 August 2019

(0)2019 American Meteorological Society

For information regarding reuse of this content and general copyright information, consult the AMS Copyright Policy.

This article is licensed under a Creative Commons Attribution 4.0 license. demonstrated that the efforts put in by the research community have led to a reduction in systematic biases and an improvement in prediction skill. A new insight that emerged from MM is that the ISMR is much more predictable than previously thought.

ISMR amounts to more than $80 \%$ of the annual rainfall over India, making it a critical lifeline for agriculture, drinking water, and energy production. The economy, life, and property in the region are vulnerable to significant variability of the ISMR on dayto-day, intraseasonal, interannual, and interdecadal time scales (Webster et al. 1998; Krishnamurthy and Goswami 2000; Goswami et al. 2006). Although the year-to-year variation of all India summer monsoon rainfall is only about $10 \%$ of the mean $(86 \mathrm{~cm})$, there is a strong link between the country's food production and the gross domestic product (GDP) with ISMR (Gadgil and Gadgil 2006). Hence, predicting ISMR at different time scales from short range (2-3 days) to medium range (up to 10 days) to extended range (2-3 weeks), seasonal, and beyond is of great socioeconomic importance. For many decades, attempts have been made but with limited success (Gadgil and Gadgil 2006; Kang and Shukla 2006). Until recently, most of these efforts involved statistical models using a variety of regression techniques (Walker 1925; Rajeevan et al. 2007; Wang et al. 2015). Statistical models, however, are built based on empirical relationships based upon past observations (DelSole and Shukla 2009) and can fail to perform satisfactorily in real-time forecasts due to either overfitting or longer-term nonstationarity (Gadgil et al. 2005). In addition, statistical model predictions asymptotically approach the "mean" and largely miss the extremes (Gadgil et al. 2005). It is also to be noted that the relationship between the predictors and predictand (ENSO and monsoon, for example) are not stationary (Kumar et al. 1999). Further, atmospheric general circulation models forced by observed sea surface temperature (SST) cannot produce realistic monsoon simulations due to their inadequacy in simulating coupled ocean-atmosphere processes (Wang et al. 2005). The coupled ocean-atmospheric modes of variabilities also control the Indian monsoon at various spatiotemporal scales. Dynamical forecasts by ocean-atmosphere coupled climate model are useful for the planners and decisionmakers in the country, even for averages like ISMR. The working hypothesis of the MM has been that the current estimate of the PPL $(\sim 0.65)$ is achievable with the reduction in model biases, and may even be too conservative since it is estimated using the same problematic models. PPL can be estimated in two ways. First, it is the perfect model correlation method 
in which the model is considered perfect, and each ensemble member deviates from the others due to an error in the initial conditions (ICs; Kumar et al. 2005). These correlation values provide an estimate of potential predictability. The other method is the analysis of variance (ANOVA; Kang and Shukla 2006), which provides a measure of predictability by calculating the ratio of external (caused by low-frequency variability, the predictable component) to internal (caused by high-frequency subseasonal variability, the unpredictable component) variance, known as signal-to-noise ratio (SNR). It has been shown that the PPL estimates for ISMR based on the above two methods are much higher than originally thought (Saha et al. 2019).

The first priority was to tackle and reduce the systematic biases of the forecast model at weather and climate time scales. Specifically, the simulation of summer precipitation exhibits a major dry bias over the Indian subcontinent, barely improving in the CMIP5 models compared to those in the CMIP3 models (Sperber et al. 2013). Seasonal prediction is possible due to the predictability arising out of the slowly varying boundary forcings such as SST, snow cover, and soil moisture (Shukla and Paolino 1983; Palmer and Anderson 1994; Webster et al. 1998). Hence, the principal approach toward reliable seasonal predictions should be to improve the simulation of the slowly varying boundary conditions such as the SSTs in the tropical Pacific and the associated teleconnections (e.g., Drbohlav and Krishnamurthy 2010; George et al. 2016; Pillai et al. 2017). New ideas were warranted to make further progress. One such new idea is that the summer monsoon intraseasonal oscillations (MISOs) act as a building block of the seasonal mean monsoon (Goswami et al. 2006, 2011) such that a large fraction of coupled model biases in simulating the mean may reflect failures in simulating the MISOs (Sabeerali et al. 2013; Sharmila et al. 2013). If so, one identified target for model development under the MM was to improve the biases in simulating the MISO. Such an improvement in MISO phenomenon is expected to deliver twin benefits, namely, better simulation of the MISOs or the active and break spells and improvements in seasonal mean ISMR. Extreme weather events (synoptic-scale systems, etc.) at short to medium time scales are also of paramount importance as these events pose the maximum threat to life and property. For this purpose, too, sophisticated global numerical weather prediction (NWP) models at very high resolution with advanced physics, dynamics, and data assimilation algorithms are required, with a focus on India's distinctive weather regimes. Resolution improvement is one easy first step, the other being physics improvement and ocean coupling. Although the representation of monsoon rainfall in initialized global NWP models has considerably improved, as a result of better representations of subgridscale physical processes, land surface processes, and increased model resolution, meaningful skill is still limited to less than 4 days (Mandal et al. 2007; Gadgil and Srinivasan 2013; Durai and Bhowmik 2014). One limiting factor to skill is the systematic error and bias of the seasonal mean in any model which builds up in the first few days of integration (weather time scale; Martin et al. 2010; Rai and Krishnamurthy 2011; Bhargava et al. 2018). Therefore, if we are able to improve the seasonal mean bias, the skill of short-, medium-, and extended-range forecasts should also improve. Improvements in atmospheric physics, dynamics, and ocean coupling must therefore go hand in hand to achieve the program goals.

OBJECTIVES. Before the MM launch (i.e., before 2010), there was no coupled ocean-atmosphere dynamical modeling framework in India to make either operational or experimental forecasts of seasonal mean monsoon and monsoon active and break cycles. Until recently, modeling activity in India was limited to standalone AGCMs and statistical models, mainly due to lack of trained personnel to work on model development and lack of adequate high-performance computing (HPC) infrastructure to run these models. Several academic and R\&D institutes in India were carrying out monsoon research, including diagnostics of why the models, both empirical and dynamical, fail to predict a particular year's monsoon performance (Rajeevan 2001; Wang et al. 2015). However, the knowledge gained from these studies had no pathway into operational weather and climate forecasts. Concerted efforts between the academic and $R \& D$ institutes and operational organizations were necessary, and this required a new initiative of national and even international scope. Bounding that scope required investing in a specific model (or at best two) with prospects for reasonably accurate forecasts and coordinating with several institutes/ organizations/universities to pursue their goals in that specific model.

Based on these strategic imperatives, MM defined the following overarching objective: to set up a stateof-the-art dynamical modeling framework and improve the skill of monsoon prediction at 1) seasonal and extended ranges and 2) short and medium ranges (up to 2 weeks).

To achieve this objective, the following two critical objectives needed to be fulfilled simultaneously: 
At an operational level, to build up a working partnership among the academic and R\&D organizations (both national and international) and the MoES institutes to improve the monsoon forecast skill over India.

At a technical level, to enhance the peak HPC capacity at the R\&D-cum-operational weather and climate prediction centers in India by four orders of magnitude between 2010 and 2017. It was estimated that in order for the R\&D centers in India to implement operationalization of state-of-the-art weather and climate predictions systems and carry on R\&D to improve their skills, the availability of HPC capacity needs to be increased from less than one teraflop in 2010 to about 1 petaflop in 2013 and further to about 10 petaflops in 2017 (Table 1 compares the computational power of major HPC systems at leading climate research centers in the world before the launch of MM in 2009).

IMPLEMENTATION STRATEGY. MoES entrusted the responsibility of overall execution and coordination of the MM to the Earth System Science Organization-Indian Institute of Tropical Meteorology (ESSO-IITM), Pune. Four MoES institutes [ESSO-IITM, ESSO-National Center For Medium-Range Weather Forecasting (NCMRWF), ESSO-IMD, and ESSO-Indian National Centre for Ocean Information Services (INCOIS)] have partnered actively in this program to realize the above objectives. The working model set up by the MoES for implementation and execution of the MM consisted of the Director of IITM as the Mission Director, advised and assisted by a Scientific Research and Monitoring Committee and guided by a Scientific Steering Committee. The ocean-atmosphere coupled dynamical model, Climate Forecast System version 2 [CFSv2, adopted from National Centers for Environmental Prediction (NCEP), United States], was chosen as the common platform for setting up prediction systems for short-range weather forecasts (using the atmosphere only component of CFS, up to 8 days in advance), extended-range predictions (a combination of CFS and its atmosphere-only component, up to 3 weeks in advance), and seasonal prediction [based on CFS, for the southwest (SW) monsoon season of June-September (JJAS)] and building an Earth system model (ESM) based on CFS for climate projections. ESSO-IITM is responsible for testing and setting up the short-range, extended-range, and seasonal predictions systems based on the CFSv2, and for model developmental activities. The IITM Centre for Climate Change Research (CCCR) dealt with the development of ESM. ESSO-NCMRWF worked on improving short- to medium-range forecasts using the Unified Model (UM) of U.K.'s Met Office (UKMO) and was also responsible for running the atmospheric data assimilation system for both UM and GFS models. MoES is a core partner in the UM partnership with UKMO, along with the Korea Meteorological Administration, Bureau of Meteorology/Commonwealth Scientific and Industrial Research Organization (Australia), and National Institute of Water and Atmospheric Research (New Zealand). The development and implementation of UM for seamless weather and climate prediction is the responsibility of NCMRWF. NCMRWF works closely with UM partners to improve the model for the Indian region and implement an appropriate suite of models for real-time use and R\&D at NCMRWF. One of the main goals is to implement a seamless modeling system at NCMRWF, covering the range from days to seasons. Ocean data assimilation system was set up at ESSO-INCOIS and provides initial conditions for different forecasts using the Global Ocean Data Assimilation System (GODAS).

To build working partnerships between the MoES organizations (ESSO-IITM, ESSO-IMD, ESSONCMRWF, and ESSO-INCOIS), and selected national and international academic and R\&D organizations, a total of 40 research projects were funded by the MoES through the MM, after appropriate review by the Scientific Review and Monitoring Committee and approval by the Scientific Steering Committee. Out of these, 20 projects were funded to institutions outside India (United States, United Kingdom, Australia, Canada, France, Japan, and United Arab Emirates). The objectives of all the projects were directed toward improving the prediction and predictability of the two chosen models (i.e., CFSv2 and UM). They were also focused on capacity building where one or two early-career scientists from the MoES organizations worked closely with each of the projects. An all-hands meeting was convened in India to synthesize results and to facilitate research-to-operations pathways in 2015.

Even though the primary target of the MM was the Indian monsoon, it is well understood that some of the key parameterizations are limited by gaps in our fundamental understanding of the underlying physical processes. As a result, a few focused observational programs of atmosphere and ocean were also supported with an intention to use this observational data to modify the existing parameterization schemes in the dynamical models. One major oceanobservation project entitled "Ocean Mixing and 
TABLE I. HPC facility at leading climate research centers in the world at the time of MM inception (top 500 list, June 201I, www.top500.org/list/20 II/06/).

\begin{tabular}{|l|l|c|}
\hline Institution & HPC & Rpeak (TF) \\
\hline Korea Meteorological Administration, South Korea & Cray XE6 & 758.0 \\
\hline INPE (National Institute for Space Research), Brazil & Cray XT6 & \multicolumn{1}{|c|}{258.0} \\
\hline NOAA/Oak Ridge National Laboratory, United States & Cray XT6 & \multicolumn{1}{|c|}{222.8} \\
\hline King Abdullah University of Science and Technology, Saudi Arabia & IBM & I48.I \\
\hline NOAA/Earth Science Research Laboratory/GSD, United States & Raytheon/Aspen Systems & I3I.I \\
\hline Japan Agency for Marine-Earth Science and Technology & NII2.8 \\
\hline European Centre for Medium-Range Weather Forecasts & I59.9 \\
\hline DOE/SC/Pacific Northwest National Laboratory & IBM & I87.6 \\
\hline National Centers for Environment Prediction, United States & IBM & 76.4 \\
\hline National Center for Atmospheric Research (NCAR), United States & IBM & 70.4 \\
\hline Indian Institute of Tropical Meteorology, India & IBM & I32.4 \\
\hline Met Office, United Kingdom & IBM & 72.8 \\
\hline Meteorological Research Institute, Japan Meteorological Agency, Japan & Hitachi & 53.9 \\
\hline Bureau of Meteorology, Australia & Oracle & IBM P6 \\
\hline MoES Institutes (NCMRWF, Noida, IMD, New Delhi and INCOIS Hyderabad)* & $\sim 45.0$ \\
\hline
\end{tabular}

*HPC strategic document of MoES, 2009, before the launch of Monsoon Mission.

Monsoon (OMM)" was funded by MoES under the MM. Finescale observations in the near-surface Bay of Bengal were gathered across seasons to understand the freshwater pathways, mesoscale and macroscale structures of Indian Ocean hydrography, and different dynamical and thermodynamic processes governing the evolution. The work under these programs is expected to lead to the improved parameterization of air-sea fluxes and upper-ocean physics in ocean models and coupled models used for diurnal to subseasonal monsoon prediction. This project also helped Indian scientists to get trained in using stateof-the-art equipment for taking in situ observations of physical processes in the ocean as well as the processing and analysis of data collected by such instruments. The preliminary results from this project are available in a special issue of Oceanography (2016, Vol. 29, No. 2). Also, three observational projects were also funded through MM as part of Indo-U.K. collaboration [MoES-Natural Environment Research Council (NERC)] to understand drivers of variability in the Indian monsoon. These projects were led in India by the Indian Institute of Science (IISc). These projects are "Interaction of Convective Organisation and Monsoon Precipitation, Atmosphere, Surface and Sea (INCOMPASS)" (Bhowmick and Parker 2018; Fitzpatrick et al. 2016; Fletcher et al. 2019; Hunt et al. 2016; Hunt and Turner 2017a; Willetts et al. 2017; Hunt and Turner 2017b; George et al. 2018), "South West Asian Aerosol Monsoon Interaction
(SWAAMI)" (Kumar et al. 2015), and "Impact of Ocean-Atmosphere Processes in the Bay of Bengal on the South Asian Monsoon (BOBBLE)" (Vinayachandran et al. 2018; Sanchez-Franks et al. 2018; Peatman and Klingaman 2018; Webber et al. 2018; Tang et al. 2017), and they are still continuing (http://mmnerc.tropmet.res.in/nerc/index.php).

MAJOR ACHIEVEMENTS. High-resolution dynamical seasonal prediction system. Under the MM program, MoES institutes now run the CFSv2, originally obtained from NCEP with a very highresolution atmospheric component, at a spectral resolution of T382 (i.e., around $38-\mathrm{km}$ horizontal resolution). This is the first time that a seasonal prediction system was run at such a high-resolution globally (Table 2), and this high-resolution model has been used to provide experimental long-range forecasts since 2011 at IITM (Srivastava et al. 2015; Ramu et al. 2016; Pai et al. 2017). The CFSv2 (Saha et al. 2014) comprises four constituent models. The GFS at a spectral resolution of T382 is the atmospheric model. The GFS has 64 hybrid vertical levels. Coupled to the GFS is the Modular Ocean Model, version 4p0d (MOM4; Griffies et al. 2004) developed at the Geophysical Fluid Dynamics Laboratory (GFDL). MOM4 also employs a dynamical sea ice model (Winton 2000). A four-layer land surface model (Ek et al. 2003) completes the CFS suite. All these components are coupled in the Earth System Modeling Framework 
TABLE 2. Resolution of the atmospheric models operational at leading climate research centers.

\begin{tabular}{|c|c|c|c|}
\hline Agency & Seasonal & Extended range & Short range \\
\hline \multirow{2}{*}{ IITM } & \multirow{2}{*}{$\sim 38 \mathrm{~km}$} & \multirow{2}{*}{$\sim 110 \mathrm{~km}$} & $\sim 12.5 \mathrm{~km}$ (deterministic) \\
\hline & & & 33 km (probabilistic) \\
\hline \multirow{4}{*}{ NCMRWF } & \multirow{4}{*}{$\sim 60 \mathrm{~km}$} & \multirow{4}{*}{$\sim 60 \mathrm{~km}$} & $\sim 17 \mathrm{~km}$ (deterministic) in 2015 \\
\hline & & & $\sim 12 \mathrm{~km}$ (deterministic) in 2018 \\
\hline & & & $\sim 33 \mathrm{~km}$ (probabilistic) in 2016 \\
\hline & & & $\sim 12 \mathrm{~km}$ (probabilistic) in 2018 \\
\hline \multirow{4}{*}{ NCEP } & \multirow{4}{*}{$\sim 110 \mathrm{~km}$} & \multirow{4}{*}{$\sim 110 \mathrm{~km}$} & $\sim 13 \mathrm{~km}$ (up to 10 days, deterministic) \\
\hline & & & $\sim 23 \mathrm{~km}$ (beyond 10 days, deterministic) \\
\hline & & & 34 km (up to 8 days, probabilistic) \\
\hline & & & $\sim 52$ km (beyond 8 days, probabilistic) \\
\hline \multirow{2}{*}{ ECMWF } & \multirow{2}{*}{$\sim 80 \mathrm{~km} *$} & \multirow{2}{*}{$\sim 36 \mathrm{~km}$} & Deterministic $(\sim 9 \mathrm{~km}) * *$ \\
\hline & & & Probabilistic $(\sim 18 \mathrm{~km})^{* *}$ \\
\hline \multirow{2}{*}{ JMA } & \multirow{2}{*}{$\sim 110 \mathrm{~km}$} & \multirow{2}{*}{$\begin{array}{l}\sim 40 \mathrm{~km} \text { (up to } 18 \text { days), } \\
\sim 55 \mathrm{~km} \text { (after } 18 \text { days) }\end{array}$} & 20 km (deterministic) \\
\hline & & & $\sim 40$ km (probabilistic) \\
\hline \multirow{2}{*}{ UKMO } & \multirow{2}{*}{$\sim 60 \mathrm{~km}$} & \multirow{2}{*}{ - } & $\sim 10 \mathrm{~km}$ (deterministic) \\
\hline & & & $\sim 20$ km (probabilistic) \\
\hline
\end{tabular}

* ECMWF switched to system 5 in November 2017 with an atmospheric model resolution of $\sim 36 \mathrm{~km}$ for seasonal forecasts.

** Short-/medium-range predictions.

(ESMF, www.earthsystemcog.org/projects/esmf/). The low-resolution CFSv2 (T126) is known to have a systematic dry bias over the Indian landmass and a cold bias over tropical ocean basins (Saha at al. 2014). An increase in the resolution of the atmospheric model of CFSv2 to T382 causes a reduced dry bias and a slight warm bias in the tropical ocean basins (Ramu et al. 2016). Analysis of hindcasts generated by this high-resolution model highlighted that the hindcasts initialized with February ICs (3-month lead) have better skill for boreal summer monsoon rainfall than other shorter leads (Chattopadhyay et al. 2016; Ramu et al. 2016; Pillai et al. 2017) and are higher for the CFSv2-T382 (MM model) compared to the original T126 (100-km resolution) version. Figure la shows the scatterplot for ISMR confirming this skill improvement with an increase of horizontal resolution of AGCM from T126 to T382 (with respect to gridded rainfall data at $1^{\circ}$ resolution supplied by the IMD for the period 1981-2010 (Rajeevan et al. 2006) and Global Precipitation Climatology Project (GPCP) rainfall data (left panel; Huffman et al. 2001). The skill of the model in simulating the countryaveraged rainfall increases from 0.50 (T126) to 0.63 (T382) with respect to GPCP. The skill scores with respect to IMD gridded data are 0.46 (T126) and 0.63 (T382). Earlier, Ramu et al. (2016) had reported the skill of the model to increase from 0.48 (T126) to 0.55 (T382) for a shorter period (1981-2008) with respect to IMD gridded data. Most importantly, they reported an improvement in the interannual standard deviation from $0.4 \mathrm{~mm} \mathrm{day}^{-1}$ (T126) to $0.5 \mathrm{~mm} \mathrm{day}^{-1}$ (T382) over a wetter India, hence illustrating a link between bias reduction and skill improvement. These improvements are attributed to better simulation of mean state, reduced systematic bias in teleconnection between Indian Ocean dipole and ISMR (Ramu et al. 2016), and improved teleconnections associated with El Niño Modoki (Pillai et al. 2017). The countryaveraged rainfall forecast is a useful metric for the socioeconomic planners and decision-makers of the country and is closely linked to the gross domestic product and food grain production in the country (Gadgil and Gadgil 2006). Prediction of seasonal mean ISMR at long lead is important during extreme monsoon years (droughts and floods) when the rainfall anomaly is homogeneous over the country (Xavier and Goswami 2007). The model skill at simulating the rainfall is reasonably good for three out of five homogenous monsoon regions of India, namely, central-northeast, northeast, and northwest (Ramu et al. 2017).

Using this high-resolution CFSv2 forecast system (henceforth referred to as the MM model), IMD successfully predicted (experimentally), the deficit monsoon of 2014 (14\% lower than long-term mean) at a lead 
time of 3 months (February IC) with a large degree of spatial agreement with observations. In contrast, forecasts from other leading climate centers suggested a near-normal monsoon during that year (Pai et al. 2017; Srivastava et al. 2015). The year 2015 was a consecutive deficit monsoon year following 2014 (12\% lower than long-term average), a rare occurrence (have occurred only thrice in the history of instrumented rainfall records from 1871 to 2013). MM model could capture the consecutive deficits of 2014/15 accurately. However, it was important to gauge the model performance over a long period of hindcasts to have confidence in the forecasts. Figure $1 \mathrm{~b}$ shows the time series of observed ISMR, IMD operational forecasts (derived from monsoon reports available at www.imd.gov.in (pages/monsoon_main.php), and MM model forecasts using NCEP ICs and the in-house atmospheric and oceanic ICs (from ESSO-NCMRWF and ESSO-INCOIS, respectively). Values are percentage departures from the mean ISMR. The MM model was able to capture the sign (positive or negative anomaly of ISMR averaged over Indian landmass) of all the extreme monsoon years accurately at 3-month lead, even though some false alarms occurred. The skill of the IMD operational forecasts (based on statistical models) for the 19882017 period is 0.36 , while the MM model skill (CFSv2 T382, $38 \mathrm{~km}$ atmospheric resolution) for the period is 0.54 , an impressive $50 \%$ increase in the skill. This is a major achievement of the MM and assumes significance, as the prediction skill of ISMR in the dynamical coupled models at the time of launching of MM was only 0.28 (in DEMETER models; Preethi et al. 2010) and 0.46 (in ENSEMBLE models; Rajeevan et al. 2012) for the 1960-2005 period, which further decreases to 0.09 postIndian land points only.
1980 (Wang et al. 2015). The high-resolution MM model is operational at IMD since 2017. The latest seasonal forecasts can be obtained from www .imdpune.gov.in/Clim_Pred_LRF_New/Models.html.

Extended-range forecast system. Active-break spells of ISMR have been predicted experimentally by ESSOIITM since 2011 up to four-pentad lead using an indigenously developed ensemble prediction system (EPS) based on the MM model. The EPS generates a large number of forecasts from different initial conditions to give the expected (mean) forecast and also the expected spreads or uncertainties in terms of probability. Forecasts are generated at every 5-day interval from 1 January of the calendar year and integrated for next 45 days. In other words, the forecast lead time is up to 45 days and is updated at an interval
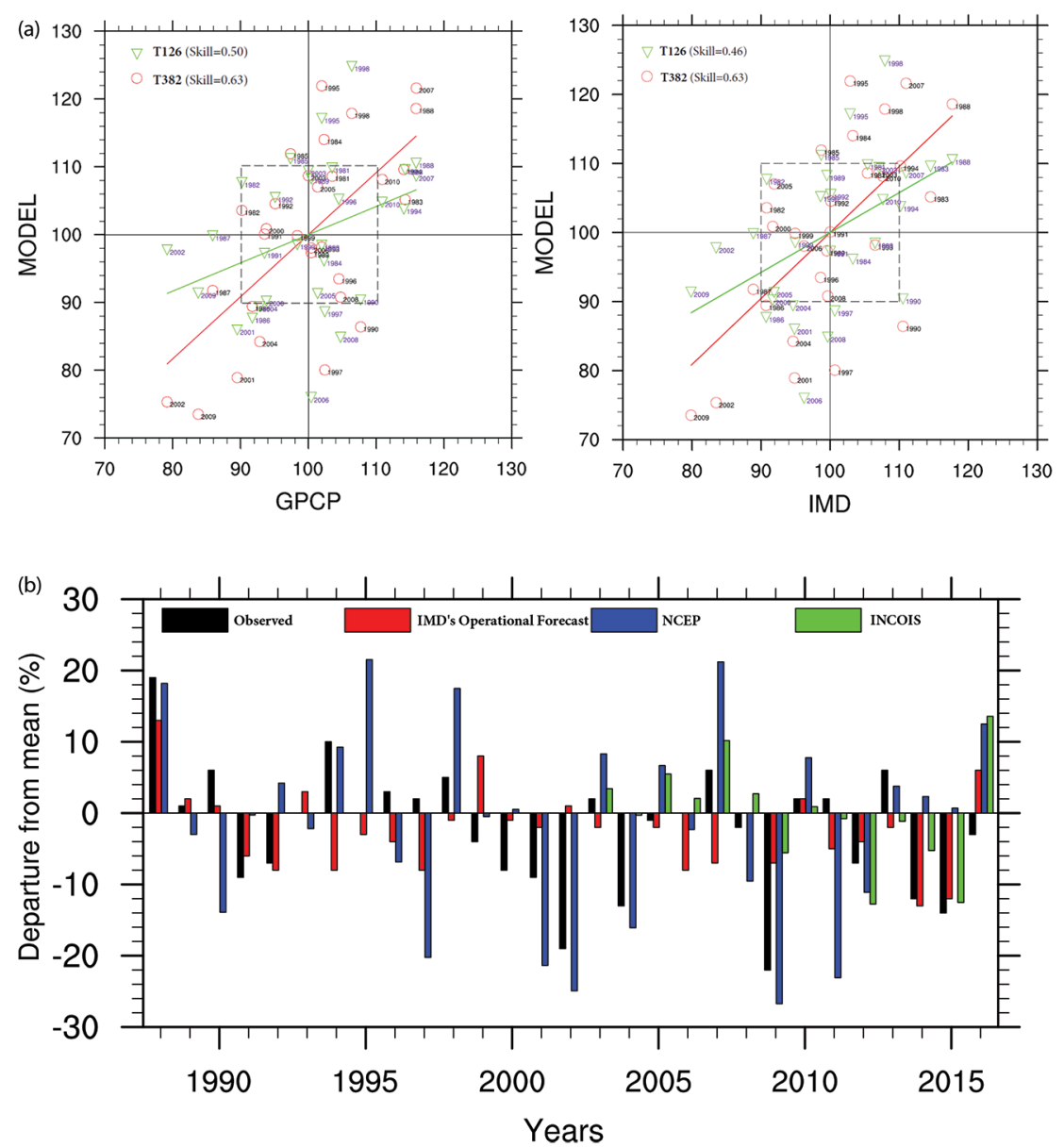

FIG. I. (a) Scatter diagram between ISMR from observations [(left) GPCP and (right) IMD] and TI26- and T382-resolution versions of CFSv2 model. The values shown are percentage departures from the mean for the summer monsoon rainfall averaged over Indian landmass. (b) Comparison of observed ISMR, operational ISMR forecast based on IMD's statistical model, and MM CFSv2-T382-predicted (hindcast) ISMR based on NCEP and INCOIS initial conditions from 1988 to 2017 . ISMR is calculated as the rainfall averaged over 
of every 5 days. Intraseasonal skill is evaluated using pentad (5-day) mean rainfall and again, a hindcast has been used to characterize the system. Figure $2 \mathrm{a}$ shows how multimodel ensemble (MME) forecasts are prepared using four variants, CFSv2 at T126 and T382 resolutions and GFS (both T126 and T382 resolutions) forced with bias-corrected SST from CFS (termed as GFSbc; Abhilash et al. 2014b). Each realization has 11 ensemble members. Model and experimental details and skills of GFSbc, CFST126, and CFST382 may be found in Abhilash et al. (2013, 2014a,b,c) and Sahai et al. (2015a,b). This experimental real-time extended-range prediction (ERP) is available at www.tropmet.res.in/erpas/. Detailed extended-range forecasts out to 20 days are shared with ESSO-IMD, which generates agricultural/

(a)

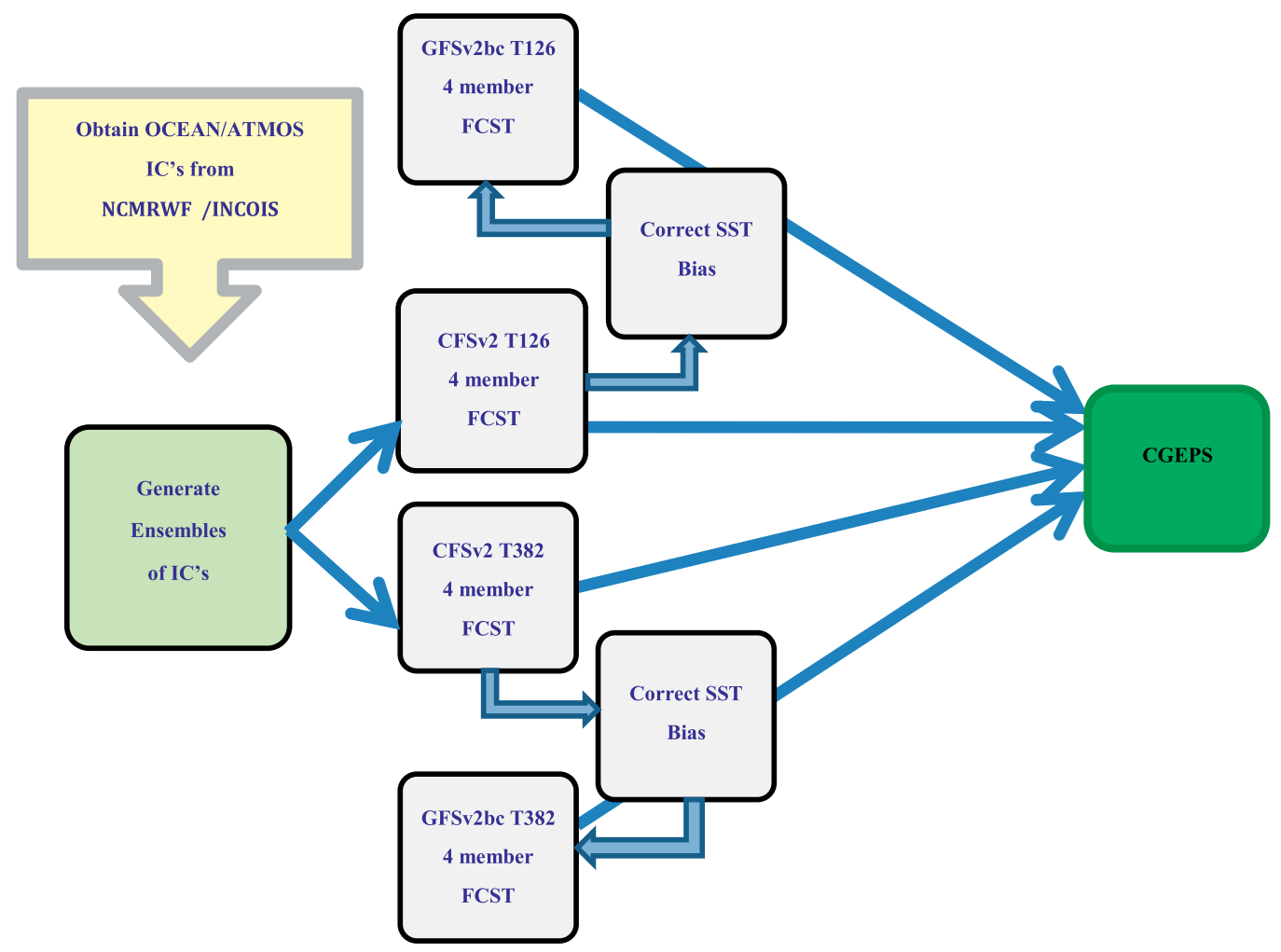

(b)
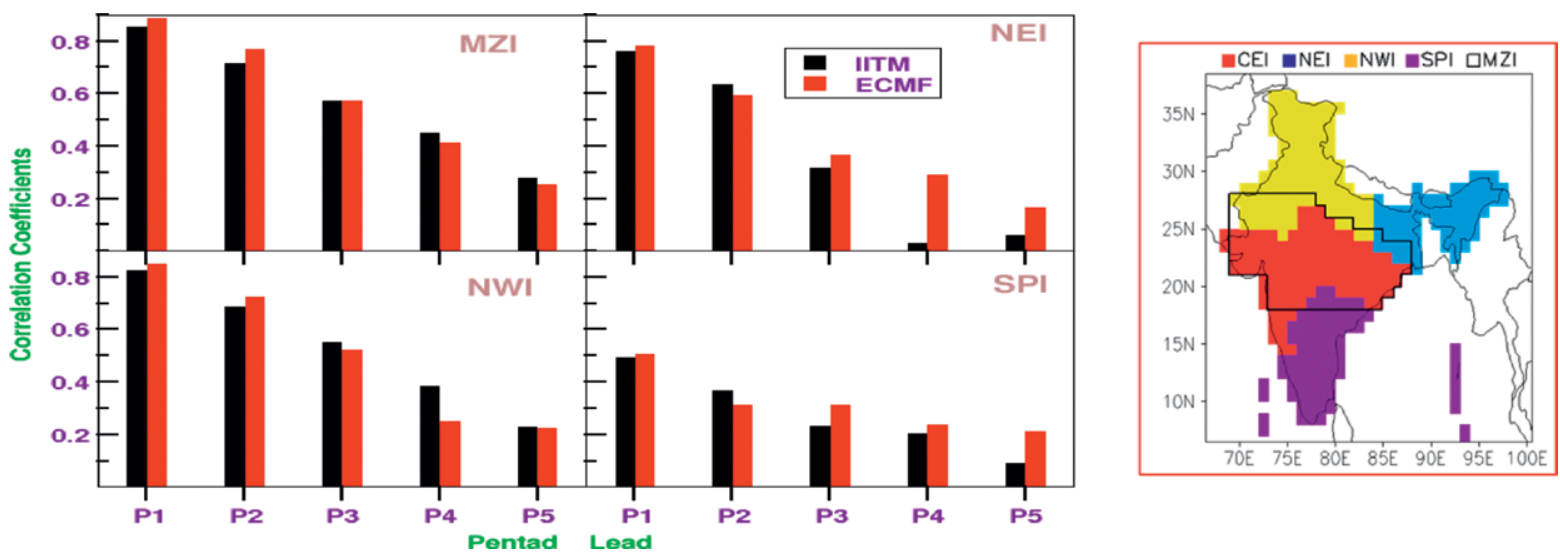

FIG. 2. (a) Schematic representation of the system adopted for extended-range prediction under MM program. The MME out of the above four suites of models are run operationally for $\mathbf{3 2}$ days based on every Wednesday initial condition with four ensemble members (one control and three perturbed) each for CFSv2T382, CFSv2TI26, GFSbcT382, and GFSbcTI26. The hindcast period is I3 years (2003-I5). (b) Pentad I (PI) to pentad 5 (P5) forecast skill of IITM extended-range prediction system and ECMWF operational system for different homogenous regions of India: the monsoon zone of India (MZI), northeast India (NEI), northwest India (NWI), and south peninsular India (SPI). 
hydrological bulletins to disseminate to the user community for planning purposes.

Various other customized forecast products are also being disseminated from this EPS, which includes active-break spells, monsoon onset, progression, withdrawal, heat-cold wave, monitoring of monsoon intraseasonal oscillations (MISO) and the Madden-Julian oscillation (MJO), cyclogenesis, and extreme rainfall events. More detailed analysis of the system can be found in Abhilash et al. (2013, 2014a,b,c, 2015a,b; 2018), Borah et al. (2015), Joseph et al. (2015a,b, 2016, 2017, 2018), Sahai et al. (2013, 2015a,b, 2016, 2017, 2019), and Saranya Ganesh et al. (2018). This ERP system is now capable of generating extended outlooks for various sector-specific applications such as agriculture (N. Chattopadhyay et al. 2018) and hydrology (Shah et al. 2017).

Hindcast verification has been done over four different regions of India, where monsoon rainfall is more or less homogeneous. The selected regions are central India (CEI), northeast India (NEI), northwest India (NWI), south peninsular India (SPI), and a broader region, the core monsoon zone of India (MZI). Figure $2 \mathrm{~b}$ compares the skill (anomaly correlation coefficient between simulated and observed) of this MM system with ECMWF prediction system (S2S ECMWF ensemble forecast data, CY41R2 version) over the different regions of India from pentad 1 to pentad 4. Since the ECMWF system has $11 \mathrm{mem}$ bers, an equal number of members were taken from the ERP system as well (three from each of CFS126, CFS382, and GFSbc126 and two from GFSbc382). IMD's station data that are gridded and merged with TRMM derived rainfall data (Mitra et al. 2013) are used as observation data. The skill of the MM system is seen to be comparable to the ECMWF system at all lead times and is slightly better in the first two pentads for SPI and NEI in spite of running at a lower resolution (R. Chattopadhyay et al. 2018).

High-resolution GEFS for short-range forecasting. The atmospheric general circulation model, namely, the GFS at T574 horizontal resolution and 64 vertical levels with semi-Lagrangian dynamical core has been used for the Global Ensemble Forecast System (GEFS) with 21 ensemble members. This system is being used to provide real-time short-range ensemble forecasts since June 2016. Initial conditions are from the Global Data Assimilation System [GDAS; the control analysis using Gridpoint Statistical Interpolation (GSI) and ensemble Kalman filter (EnKF) hybrid analyses] and the 20 ensembles from the EnKF scheme. These data assimilation systems are being run at NCMRWF,
Noida. Therefore, a total of 21-member forecast is run for 10 days with GFS semi-Lagrangian model. The postprocessing is done at three different resolutions for operational use. IMD forecast offices at New Delhi and other centers extensively used this forecast during the 2016 southwest monsoon period. Since then, a very high-resolution T1534 $(\sim 12.5 \mathrm{~km}$, Table 2) deterministic forecast system has also been set up for short-range (10 days) predictions using GFS. A schematic of this system is illustrated in Fig. 3a. This short-range deterministic forecasting system has been transferred to IMD for operationalization

(a) SCHEMATIC OF GFS (SL) T1534 L64 RUNNING

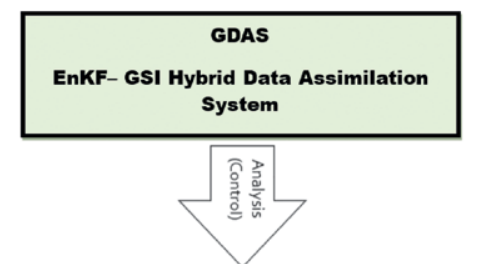

FORECAST: GFS Semi- Lagrangian T1534 (approx. $12.5 \mathrm{~km}$ at equator)

L64 vertical resolution

Runs for 240 hrs (10 days)

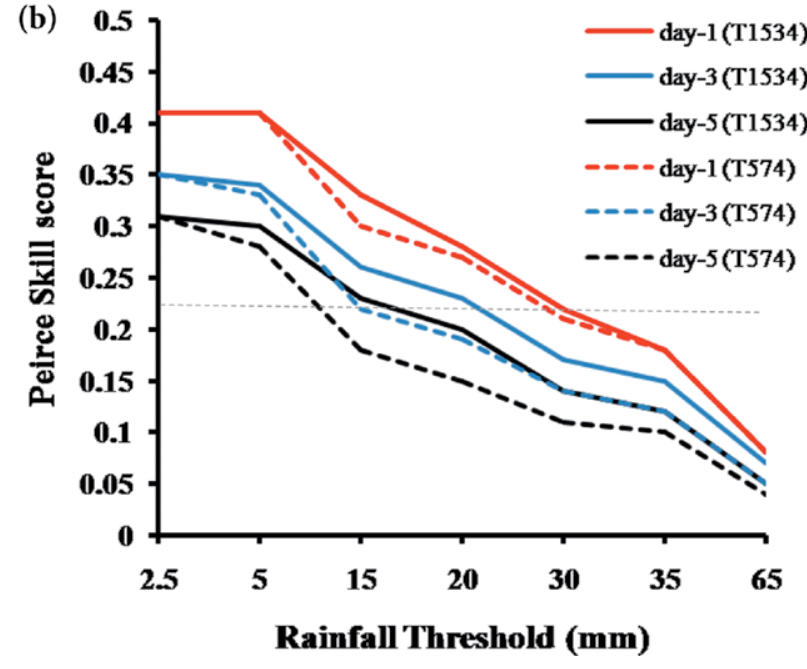

FIG. 3. (a) Schematic representation of GFS (SL) TI534 L64 running AT IITM. (b) Forecast skill (Peirce skill score) for different rainfall threshold values for day I, day 3, and day 5 forecast of GFS system of MM for different resolutions (TI534 and T574). 
since January 2017. Apart from IMD, a mirror site for the forecast graphics is available at http://srf.tropmet .res.in/srf/files/archive_hires.php. The location and intensity of extreme rains as well as cyclogenesis events have been forecasted with some success at reasonable lead time. Figure $3 b$ shows that this deterministic GFS forecast system with a resolution of T1534 can increase this measure of forecast skill by up to 2 days (solid dark line above dashed blue line) compared to its lower-resolution version T574 (Fig. 3b). The skill score has been computed with respect to IMD's station data that are gridded and merged with TRMM derived rainfall data (Mitra et al. 2013). Societal applications, like agriculture, energy sector, and forest fire monitoring and forecasting are being benefitted from its $12.5-\mathrm{km}$ resolution. A high-resolution T574 (semi-Lagrangian core) GEFS for short-range forecast with 21 ensemble members has also been set up, for which ESSO-IITM, ESSONCMRWF, and ESSO-IMD have worked together. This system is being used to provide real-time shortrange ensemble forecast since June 2016. Recently, after the completion of MM phase 1, a high-resolution ensemble prediction system based on GEFS at T1534 $(\sim 12.5 \mathrm{~km})$ resolution with 21 ensemble members has also been set up for issuing probabilistic short-range forecast up to 10 days.

IITM-ESM. It is important to understand the impact of changing climate on the Indian monsoon. For reliable future projections of the Indian monsoon rainfall in a changing climate, the successful CFSv2 model (as described above) has been transformed to an Earth system model (IITM-ESM) (Swapna et al.

(a) SAT (Obs)
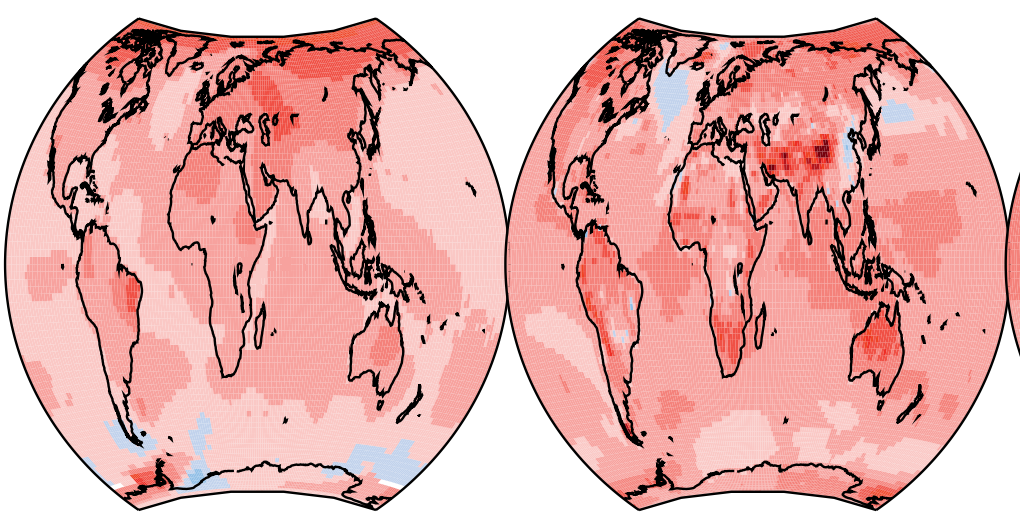

(b) IITM-ESM

(c) IITM-ESM (2C02)
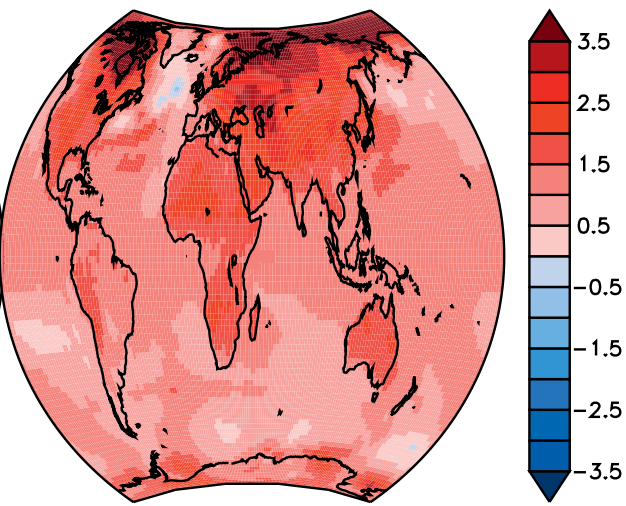

(d) Precip (JJAS,Obs)

(e) IITM-ESM

(f) IITM-ESM (2CO2)
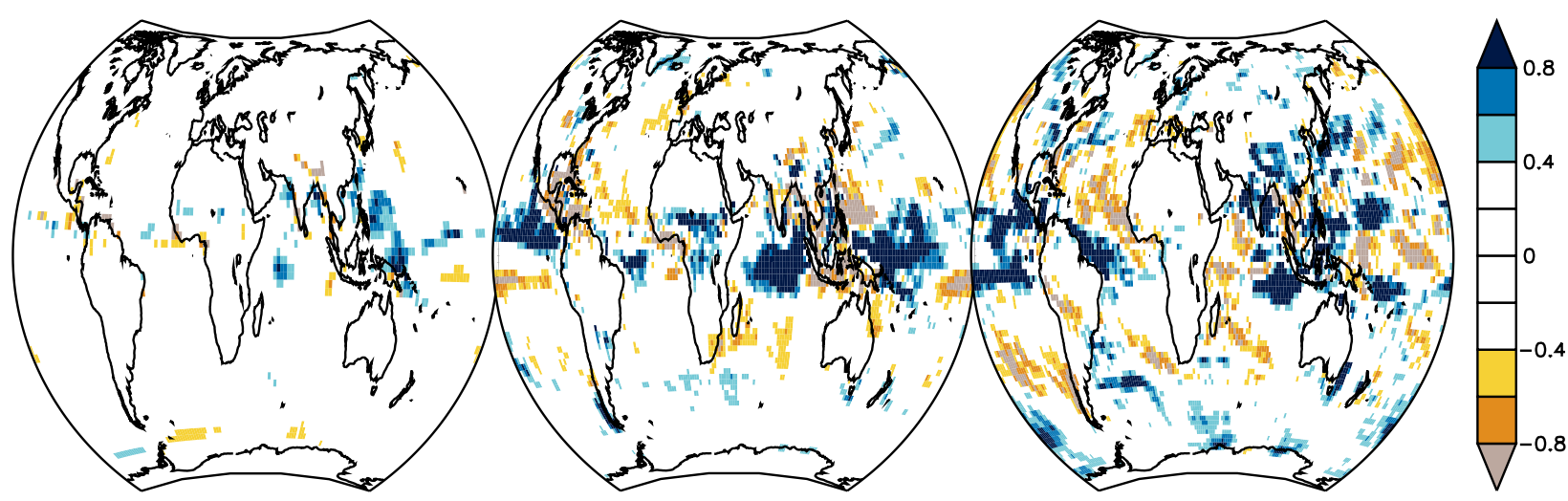

Fig. 4. Spatial map of (a)-(c) annual mean surface air temperature $\left({ }^{\circ} \mathrm{C}\right)$ and $(\mathrm{d})-(\mathrm{f})$ summer monsoon (JJAS) precipitation ( $\mathrm{mm}$ day $^{-1}$ ) anomalies in (a),(d) observations (GISS temperature and GPCP precipitation datasets); (b),(e) IITM-ESM present-day simulation based on the 2005 values of GHGs, aerosols, and land cover; and (c),(f) $2 \times \mathrm{CO}_{2}$ experiment from IITM-ESM. Observed anomalies are for the period 2000-17 with reference to base period of 1980-2017. The IITM-ESM anomalies are based on the 50-yr mean of 2005 control minus the 50 -yr mean of 1850 control integration. 
2015, 2018; Krishnan et al. 2019). Figure 4 shows the annual mean surface air temperature and summerseason (JJAS mean) precipitation anomalies (relative to preindustrial control) simulated by the IITMESM's present-day control simulation based on the 2005 values of greenhouse gases, aerosols, and land cover (center panels). For comparison, the results from $2 \times \mathrm{CO}_{2}$ experiment are shown (right panels) along with observed anomalies (at left) for the period 2000-17 with respect to the base period of 1980-2017. The IITM-ESM anomalies are relative to the preindustrial control experiment (Swapna et al. 2018). The latest version of the IITM-ESMv2 is contributing to the Coupled Model Intercomparison Project phase 6 (CMIP6) for the Intergovernmental Panel on Climate Change (IPCC) Sixth Assessment Report (AR6) - the first such contribution from India. The IITM-ESMv2 is a radiatively balanced modeling framework capable of providing useful projections of climate sensitivity and the global and regional hydrological responses to the radiative effects of anthropogenic forcing due to greenhouse gases (GHGs), aerosols, and land-use/ land-cover changes. The radiatively balanced framework was achieved by incorporating the effects of viscous dissipation of turbulent kinetic energy (TKE) in the atmospheric model of the IITM-ESMv2, refinements in flux computations over ice-covered regions, implementation of fractional grids for exchange of fluxes between atmosphere and other component models, and realistic simulation of the Atlantic meridional overturning circulation (AMOC). The IITMESMv2 also has good representations of the Arctic sea ice cover and ENSO-monsoon teleconnections, among other important modes of climate variability (Swapna et al. 2018; Krishnan et al. 2019).

Data assimilation. Sustained observations are vital for data assimilation to provide robust initial conditions for dynamical models. ESSO-INCOIS contributed to MM by operationalizing NCEP's Global Ocean Data Assimilation System (GODAS) based on the GFDL's MOM4.0 and a three-dimensional variational (3DVAR) data assimilation scheme (INCOISGODAS; Ravichandran et al. 2013). The 3DVAR assimilation scheme is used to assimilate observed temperature and salinity profiles, in the top $700 \mathrm{~m}$, from observational platforms like Argo, moored buoys, and ship-based observations. GODAS is forced with four-times-daily atmospheric fluxes from NCMRWF at a spectral resolution of T574, which amounts to a spatial resolution $\left(0.25^{\circ} \times 0.25^{\circ}\right)$. MMsupported enhancements include GODAS analyses with improved model resolution, a shorter assimilation window, and a shorter relaxation time scale (5 days), with additional data in the Indian Ocean through their ocean observations and assimilation system (Ravichandran et al. 2013). This system's outputs are being used to initialize the MM coupled models. Most of the observed features of temperature, anomalous sea surface height (SSHA), and currents are reflected well in the tropical Indian Ocean at both intraseasonal and interannual time scales. Further R\&D will improve these products by incorporating a local ensemble transform Kalman filter (LETKF) technique in the plume of 3DVAR. A coupled data assimilation system based on CFS-LETKF (Sluka 2018) has been set up at ESSO-IITM. The system at present is a weakly coupled system. A strongly coupled ocean-atmosphere data assimilation system (Sluka 2018) is a challenge, being addressed by ESSO-IITM with active collaboration and coordination with the University of Maryland and ESSO-INCOIS. Initial 2-yr outputs show that the root-mean-square error has reduced by about $0.2^{\circ}-0.4^{\circ} \mathrm{C}$ globally as compared to the NCEP GODAS (P. Sreenivas 2019, personal communication), except in the extratropics. Taking advantage of the HPC resources set up under MM, the atmospheric data assimilation system along with the model frameworks used have been upgraded from time to time (Table 3; Prasad and Johny 2016; Prasad et al. 2016). To support these high-resolution assimilation systems, the data reception systems have been strengthened by establishing direct data connectivity with bulk meteorological satellite operators, such as the National Oceanic and Atmospheric Administration (NOAA)/National Environmental Satellite, Data, and Information Service (NESDIS) and the Indian Space Research Organization (ISRO). This is in addition to the meteorological observations from all 
over the globe that are received at the Regional Telecommunication Hub (RTH), New Delhi, through the Global Telecommunication System (GTS). Further, the European Organisation for the Exploitation of Meteorological Satellites's (EUMETSAT) terrestrial reception system (EUMETcast) was also established to receive data from EUMETSAT. This terrestrial reception system supports data reception from Japan and China as its third-party services. Thus, the data being assimilated at ESSO-NCMRWF has grown immensely due to the efforts under MM, improving the quality of the analysis hence generated. After data thinning (satellite data) and quality control, $\sim 5$ gigabytes $(\mathrm{GB})$ of data were being assimilated in the GFS-based assimilation cycle, and the same has now increased to $\sim 17 \mathrm{~GB}$. Using the atmospheric ICs from NCMRWF and oceanic ICs from INCOIS, the seasonal forecast model is integrated for 9 months using a lagged ensemble method. The perturbed atmospheric ICs and oceanic ICs are used for extended-range forecasts. The atmospheric initial conditions (perturbed atmospheric ICs) from NCMRWF are used for deterministic (probabilistic) short-range forecasts as well.

Technical advancement. As discussed at the outset, MM emphasized the need for HPC resources not only for operational multiscale predictions and climate, but also for R\&D to improve the models for all these ranges of predictions. In 2013, two HPC systems

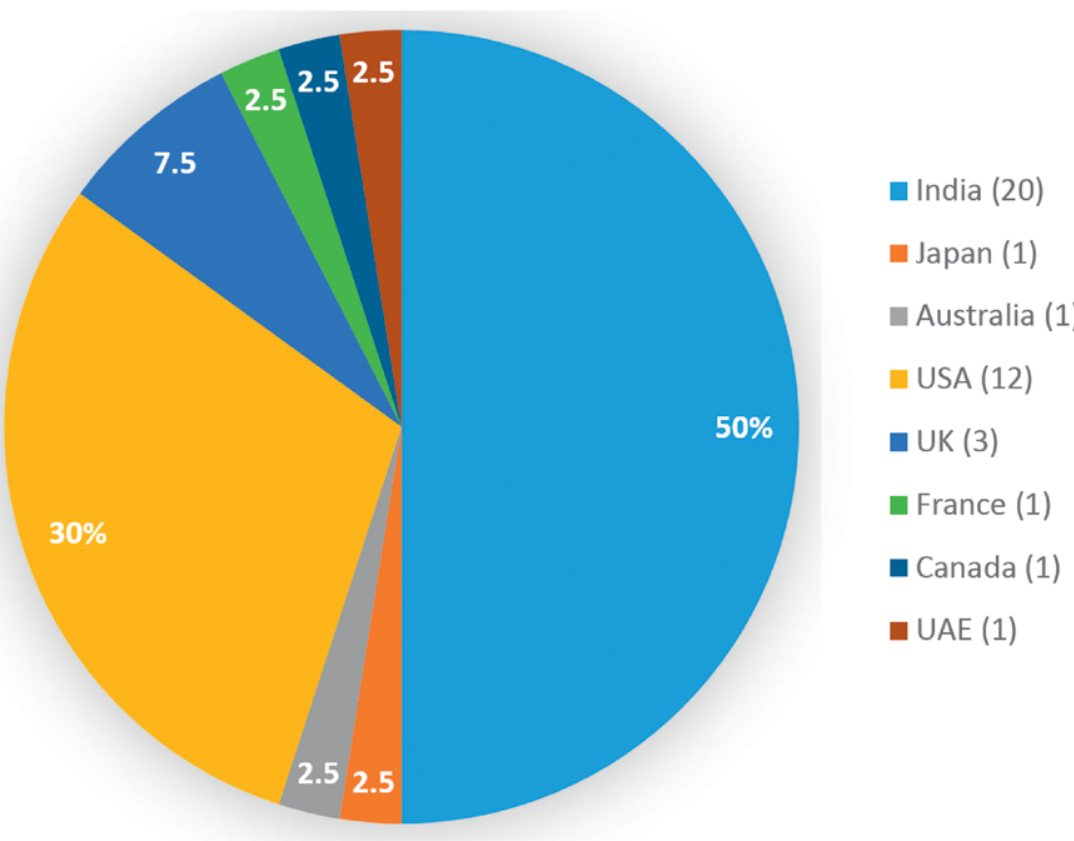

FIG. 5. A pie diagram showing the countrywide distribution of the 40 research projects funded under the MM. The numbers in parentheses denote the number of projects allocated to that country.
[790 teraflops (TF) "Aaditya" HPC at ESSO-IITM and $350 \mathrm{TF}$ at ESSO-NCMRWF] have been successfully procured and utilized as illustrated above. It is thus clear that adequate computational infrastructure is a necessary condition for better forecasts. Transformatively, the next upgrade took place in February 2018 with two new HPC systems (4006 TF "Pratyush" at ESSO-IITM and 2808 TF "Mihir" at ESSO-NCMRWF) were added, keeping the program's science and operational goals feasible technically as expertise keeps growing.

\section{R\&D toward improving ISMR prediction and predictability.}

The nationwide distribution of the 40 research projects funded under MM is shown in Fig. 5. In addition to carrying out some sensitivity experiments, various national and international projects funded through MM studied the hindcast products and long control simulations of the MM model. Biases and processes in the simulation of SST, rainfall, intraseasonal oscillations, ENSO-monsoon relationship, cyclone tracks, and other phenomena have been explored. Experiments with embedded regional models at weather and cloud-resolving scales have illuminated multiscale variability and its implications for predictability. Downscaling (at 10-km resolution) of seasonal monsoon forecasts using stand-alone and regionally coupled (ocean-atmosphere) models have been studied to understand the local and remote drivers of regional monsoon variability. Different oceanland-atmosphere coupling and initialization strategies were tested to improve monsoon prediction in the model. Such studies have improved the understanding and representation of various processes at short, medium, and long ranges contributing to global science as well as for the benefit of the Indian public.

One of the major shortcomings of the models that MM targeted was simulating the MISOs, with the other being to reduce the systematic biases in the model. MISOs are considered to be the building blocks of the Indian summer monsoon 
(Goswami et al. 2006), with implications extending to the seasonal mean bias. The prediction of MISOs at extended-range time scales had remained a challenging problem for the operational monsoon forecast community. The extendedrange prediction group came up with a multimodel ensemble prediction system that could improve the spread-error relationship in the forecasts (Abhilash et al. 2015a,b). The multimodel ensemble, as well as its individual contributing models, have reasonable skill in predicting the JJAS rainfall over various homogenous regions throughout India [viz., central India, the monsoon zone of India (Rajeevan et al. 2010), northeast India, northwest India, and the south peninsula (Abhilash et al. 2014a,b,c, 2015a,b; Sahai et al. 2013, 2015a,b)]. The skill of the EPS in predicting extreme rainfall events during summer monsoon has been reported in Joseph et al. (2015a). It is also known that cloud microphysics plays an important role in the organization of convection on the MISO scale (Kumar et al. 2017). So, efforts were focused on changes to convection parameterization [utilization of revised Simplified-Arakawa-Schubert (SAS) scheme]. Wide-ranging and novel approaches were explored under MM support, including stochastic multicloud parameterization, application of superparameterization schemes and cloud microphysics schemes, and many more. CFSv2 is known to simulate a systematic dry bias over Indian landmass (Saha et al. 2014). Goswami et al. (2015) reported that the synoptic variance is underestimated in the model compared to ISO variance, and pointed toward possible deficiencies in the convection parameterization schemes. Therefore, experiments were carried out using a revised SAS scheme based on Han and Pan (2011). The revised convection parameterization scheme (CPS) has shown improvements in the annual seasonal cycle, onset, and withdrawal and the rainfall probability distribution function (PDF) due to the better diurnal cycle of convection and associated convective rainfall (Ganai et al. 2015). Improvements are also noted in the diurnal features of monsoon during active and break phases (Ganai et al. 2016). To address the unresolved features of organized tropical convection, a stochastic multicloud model (MCM) was developed by Khouider et al. (2010). This was implemented in CFSv2 (Goswami et al. 2017b). CFS-MCM shows improvement in the synoptic and intraseasonal variability, MJO, convectively coupled equatorial waves, and the Indian summer MISO (Goswami et al. 2017a,c). Taking into consideration the systematic biases of CFSv2 in simulating observed Boreal summer intraseasonal oscillation (BSISO) features and to test the observation-based hypothesis of Jiang et al. (2011) and Abhik et al. (2013), Abhik et al. (2017) revised the cloud processes in the model by employing the revised CPS and by incorporating a six-class hydrometeor scheme (WSM6; Hong and Lim 2006) suitably modifying the critical mean droplet radius in the rain autoconversion formulation following the in situ observations of the Cloud-Aerosol Interaction and Precipitation Enhancement Experiment (CAIPEEX; Kulkarni et al. 2012), enabling the model to generate gridscale tendencies of cloud hydrometeors. These changes resulted in a realistic simulation of BSISO over the Indo-Pacific region, reduction in systematic biases in CFSv2, convective-stratiform rainfall distribution, 
and reproduction of the observed relation of MISO and cloud hydrometeors (Ganai et al. 2019). This modified version (at $\mathrm{T} 126$ resolution) shows the skill comparable to CFSv2 T382, though the interannual variance is slightly overestimated (Fig. 6). Hazra et al. (2017) the used observations from CAIPEEX (Kulkarni et al. 2012) and made major modifications to the existing Zhao and Carr (1997) cloud microphysics scheme in the CFSv2. This was undertaken to address the inadequacy of the model in simulating the mixed-phase hydrometeors and the ratio of convective to stratiform rainfall, which has a bearing on the simulation of MISOs. The modified microphysics of Hazra et al. (2017), revised SAS of Han and Pan (2011), and observation-based modified critical relative humidity (De et al. 2016) was tested in retrospective forecast mode, and improvements in the seasonal forecast skill were reported (Pokhrel et al. 2018). Another major monsoon-affecting bias was the excessive snow simulation over the Eurasian region by CFSv2, which reduced the north-south temperature gradient and resulted in the simulation of a weak monsoon (Saha et al. 2013). Replacing the single-layer snow scheme with a six-layer surface snow model and implemented in the CFSv2 yielded a more realistic simulation of snow over Eurasia and an improved Indian summer monsoon (Saha et al. 2017). These results are also summarized in Table 4. Through such efforts, progress has been steadily made on many fronts.

To test the impact of the progress made under $\mathrm{MM}$, a series of hindcast experiments were carried out using seven versions of the MM model with mixed physics configurations, namely, 1) the standard CFSv2 at T126 resolution with standard physics (CTL; Saha et al. 2014), 2) with the high-resolution (T382) MM model (Ramu et al. 2016), 3) with revised SAS, improved cloud microphysics (WSM6) and radiation (Abhik et al. 2017), 4) with old snow model but new cloud microphysics parameterization (MC; Hazra et al. 2017), 5) with new snow model combined with new cloud microphysics (SN-MC; Saha et al. 2019), 6) with the revised convection parameterization scheme (SAS2; Han and Pan 2011; Krishna et al. 2019), and 7) the revised convection parameterization scheme and revised shallow convection scheme (SAS2sc). These hindcasts were carried out for the period 1981-2010. Thanks to the HPC capacity, the control runs reported in Ramu et al. (2016) could be carried out again to match the hindcast period of the rest of the runs. Results from these massive seasonal reforecast experiments (Fig. 6) indicate that all these modifications contributed to improvement of the skill of seasonal forecasts of ISMR, with scores approaching $\sim 0.71$, much higher than the skill of the original model with which we started MM (CTL run, $R \sim 0.49$, all the skill scores are reported with respect to IMD $1^{\circ}$ gridded data; Rajeevan et al. 2006). It is also worthwhile to note that the high-resolution MM run reproduces an interannual variability very close to observations, in addition to simulating a high ISMR prediction skill (0.63). This is reflected in reforecasting extreme drought years in 2002, 2004, and 2009 in Ramu et al. (2016). This highlights the importance of using a high-resolution model for droughts as well as pluvial signals, as was originally envisioned at the outset of MM. The reforecast with the revised version of CFS at coarser resolution (CFSv2T126; Abhik et al. 2017) also shows a skill score of 0.62 (WSM6 in Fig. 6), though the interannual variability is slightly overestimated $(1.09$, ratio of standard deviation of simulated ISMR to the observed), which demonstrates that even a coarserresolution model with improved cloud, convection, and radiation physics parameterization can achieve enhanced skill. SN-MC (Saha et al. 2019), SAS2sc (Krishna et al. 2019), and MC (Hazra et al. 2017) also simulate higher skill scores of $0.62,0.65$, and 0.71 , respectively, which demonstrates an improvement over the control run, even though the interannual variance is underestimated. Some of the model development activities mentioned above are in the process of being incorporated in the high-resolution MM model, and we hope that their inclusion will further enhance the country-averaged ISMR prediction skill and the spatial skill of the model, although the possibility of compensating errors requires that this be tested carefully. Developmental activities conducted both in-house and by various participating institutes, which led to the abovementioned scientific improvements, are tabulated in Table 5. Interestingly, the MM model has a reasonably good skill for the country-averaged rainfall, as well as the homogenous regions of India, except for southern peninsular India (Ramu et al. 2017).

In the ocean, the parameterization of vertical mixing is a challenge in complex scenarios such as the low-salinity regions in the Bay of Bengal (BoB). A key science question is how the enormous amount of freshwater introduced at the surface in the north BoB from local rain as well as from the major rivers like Ganga-Brahmaputra discharge gets transported to the south by the mesoscale eddies and gets mixed with deeper layers in the highly stratified background. Using the data from the observational campaigns funded under OMM, new insights have 
TABLe 4. Summary of model developments.

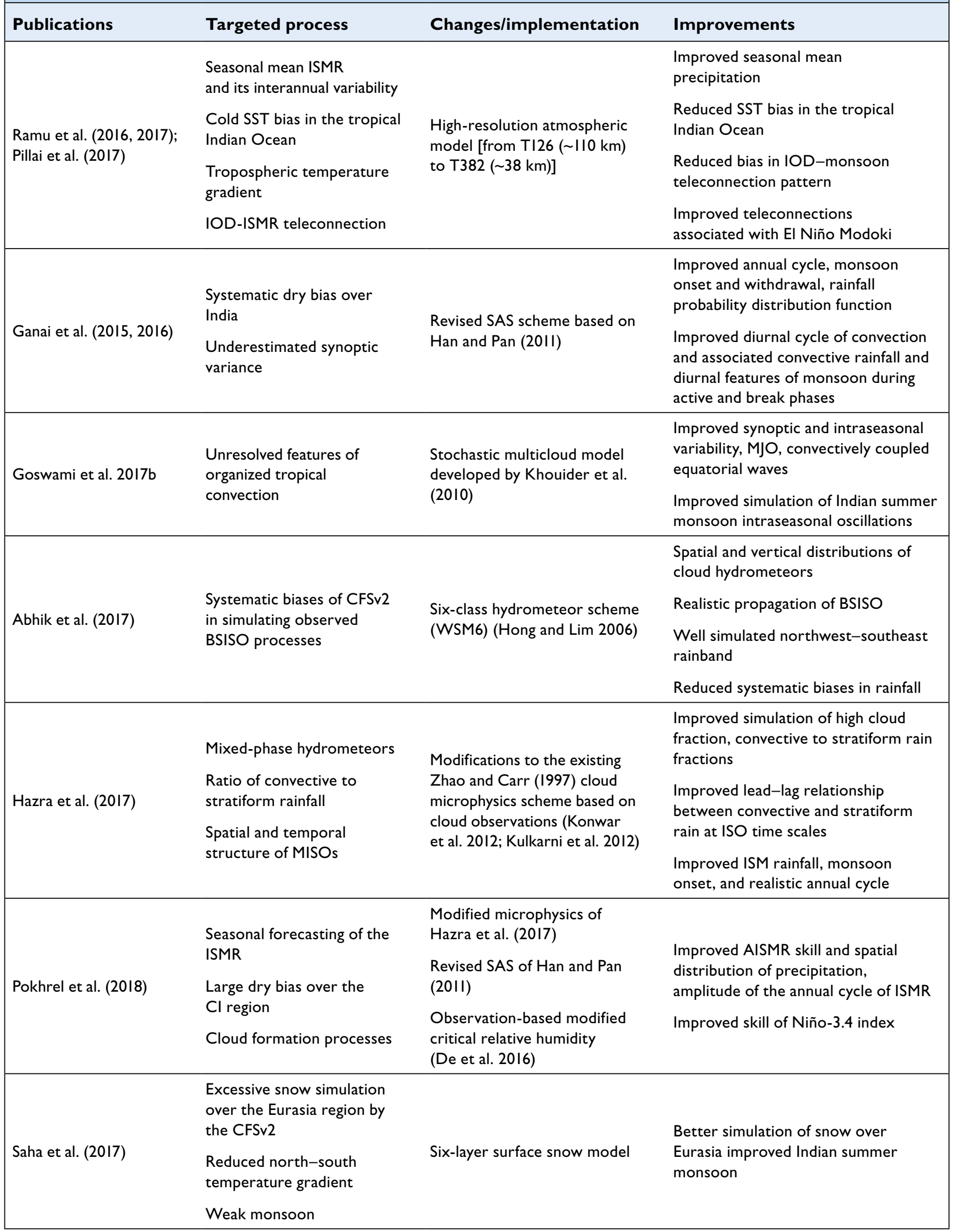


TABLE 5. Developmental activities under Monsoon Mission.

\begin{tabular}{|c|c|c|}
\hline Proposed activity & $\begin{array}{l}\text { Completed during } \\
\text { Monsoon Mission }\end{array}$ & Ongoing \\
\hline \multirow{4}{*}{$\begin{array}{l}\text { Setup of CFSv2 prediction } \\
\text { system }\end{array}$} & $\begin{array}{l}\text { High-resolution (T382) seasonal prediction system } \\
\text { (Ramu et al. 2016) }\end{array}$ & \\
\hline & $\begin{array}{l}\text { Grand MME prediction system for extended-range } \\
\text { prediction of monsoon (Sahai et al. } 2013,2015 a, b)\end{array}$ & \\
\hline & $\begin{array}{l}\text { A very high-resolution T574 and TI534 (semi- } \\
\text { Lagrangian core) Global Ensemble Forecast } \\
\text { System (GEFS) for short-range forecasts }\end{array}$ & \\
\hline & $\begin{array}{l}\text { CFSv2 seasonal forecast model transformed into an } \\
\text { Earth system model (IITM-ESM) suitable for long- } \\
\text { term climate change studies (Swapna et al. 20I5, 20I8; } \\
\text { Krishnan et al. 20I9); although not formally funded } \\
\text { under MM, the development of IITM-ESM is } \\
\text { essentially a by-product of sustained in-house climate } \\
\text { model development efforts at the CCCR, IITM }\end{array}$ & \\
\hline \multirow{4}{*}{$\begin{array}{l}\text { Developmental activities to } \\
\text { improve the original model } \\
\text { performance }\end{array}$} & $\begin{array}{l}\text { New convection parameterization scheme (SAS2, } \\
\text { Han and Pan 20II; Ganai et al. 2015, 2016; Krishna } \\
\text { et al. 2019) to replace the original SAS scheme } \\
\text { Modified cloud microphysics (ice and cloud } \\
\text { microphysics, Phani et al. 2016, Abhik et al. 2017, } \\
\text { Hazra et al. 2017, Saha et al. 2018, Pokhrel et al. 2018) }\end{array}$ & \multirow{4}{*}{$\begin{array}{l}\text { New high-resolution ocean model } \\
\text { EnKF-based coupled data } \\
\text { assimilation system }\end{array}$} \\
\hline & $\begin{array}{l}\text { Super parameterization in CFS (SP-CFS, } \\
\text { Goswami et al. 20I5) } \\
\text { Multilayer snow scheme in the land surface model } \\
\text { (Saha et al. 2017) }\end{array}$ & \\
\hline & $\begin{array}{l}\text { Stochastic parameterization } \\
\text { (Goswami et al. 2017a,b,c) }\end{array}$ & \\
\hline & $\begin{array}{l}\text { Weakly coupled data assimilation system } \\
\text { (Sluka et al. 2016) }\end{array}$ & \\
\hline
\end{tabular}

emerged from a recent study (Sree Lekha et al. 2018) indicating the key role of the monsoon subseasonal oscillations in this process. The annual freshwater input from monsoonal rains and rivers creates a stable upper-ocean stratification which is known to influence the air-sea interaction in the region (Shenoi et al. 2002; Vinayachandran et al. 2002; Rao et al. 2011). The shallow fresh layer persists in the BoB for nearly three seasons until winter. The dispersal of the river water is closely related to the changes in the monsoonal subseasonal winds (quasibiweekly). When the monsoon winds strengthen, a shallow (10 m deep) wind-driven Ekman flow moves the river water to the north and east, while in the phase of weak winds, the river water is moved mainly by the mesoscale eddy flow (Fig. 7). To understand the submesoscale and microstructure of temperature and salinity, several campaign mode observations were made. A moored buoy with highly sophisticated instruments for high-frequency continuous measurements was deployed in the north BoB supplemented by several unmanned aerial vehicle (e.g., gliders) transects. These observations have brought out fascinating new details about the mesoscale and submesoscale processes in the BoB, providing challenges and guidance for parameterizations. This data are being utilized to improve the representation of these processes in the ocean models. Many of these observational findings are reported in a special issue of Oceanography (2016, Vol. 29, No. 2). This has also highlighted that the freshwater fluxes into the ocean are an important component of the Earth system and are closely associated with monsoon processes, especially in the BoB. Therefore, the inclusion of this coupling in the MM model is an emphasis in the second phase of MM. 


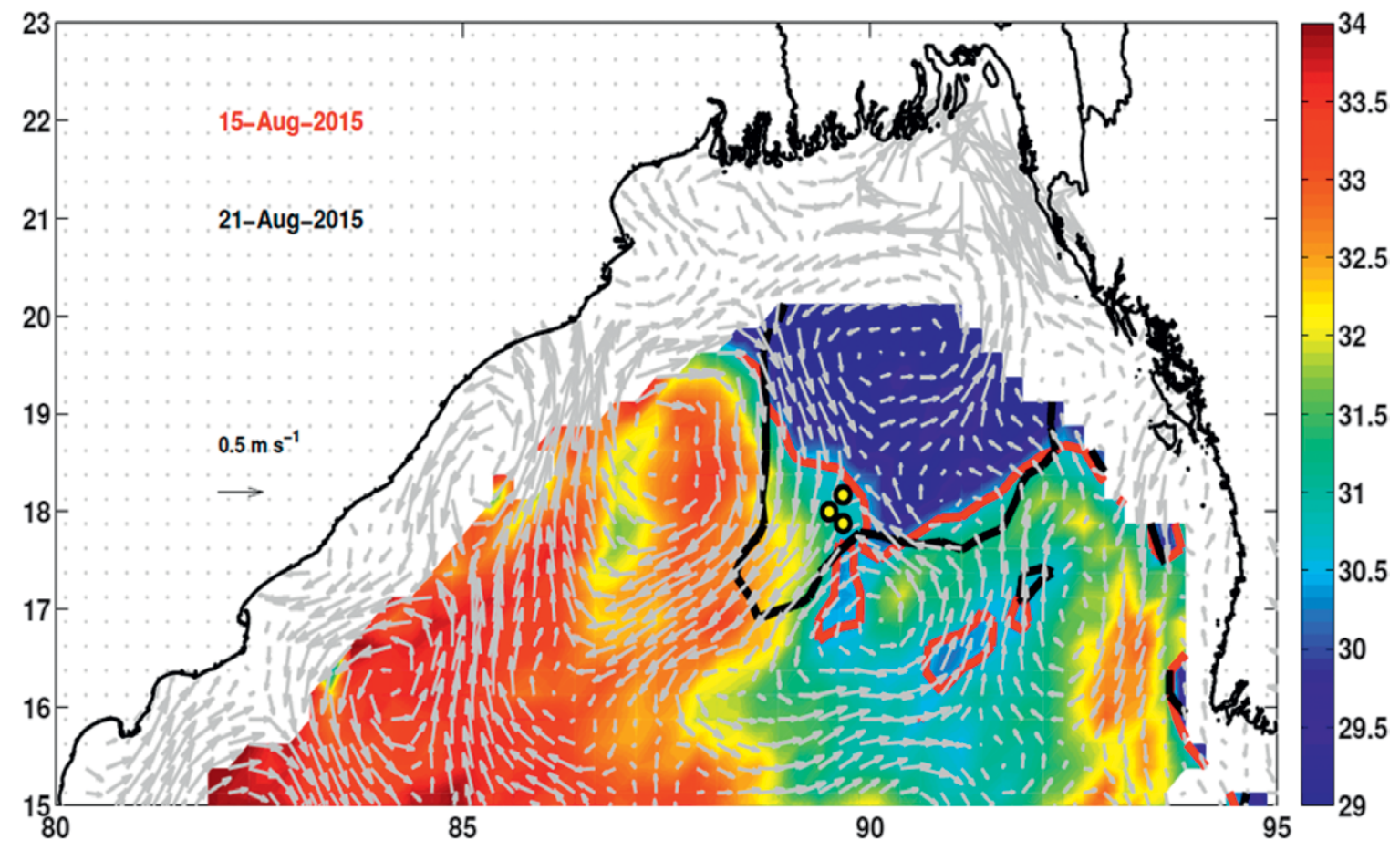

FIG. 7. River water from the Ganga-Brahmaputra (blue colors) in a map of sea surface salinity (SSS) from the SMAP satellite on 15 Aug 2015. When monsoon winds are low, river water is moved by the flow between two mesoscale ocean eddies (current vectors; gray). The 30.5-psu contour moves by nearly $200 \mathrm{~km}$ in 6 days (speed $=0.35 \mathrm{~m} \mathrm{~s}^{-1}$ ) between 15 Aug (red contour) and 21 Aug 2015 (black contour).

SUMMARY AND CONCLUSIONS. Motivated by India's need for global models to represent its monsoon better, in order to improve forecast and gain skill that was known to be possible to achieve, the MM program was launched in 2012. In less than a decade, fueled by leaps in HPC and its use by creative researchers in league with motivated institutions, the successful implementation of the Monsoon Mission resulted in the following achievements:

- A high-resolution global coupled model is now issuing operational seasonal forecasts of Indian summer monsoon rainfall with high skills $(>0.6)$ over the Indian land region (Fig. 6, Table 2).

- A new operational extended-range coupled prediction system yields prediction skills comparable with the leading operational centers in the world (Fig. 2b).

- A very high-resolution probabilistic short-range prediction system based on GEFS $(\sim 12.5 \mathrm{~km}$, Table 2) and a deterministic GFS (semi-Lagrangian at $12.5 \mathrm{~km}$ ) are providing skillful forecasts.

- A strongly coupled data assimilation system based on LETKF has been set up and is being optimized to provide better initial conditions for the operational models.
- Numerous model developmental activities have been carried out, not only to reduce the systematic model biases but also to improve the prediction skill of the monsoon weather and climate.

- Phenomenological studies have illuminated processes from mixing to MISOs from both observational and model perspectives.

- Development of ESM for climate projections.

A comparison of the resolution of MM models with those operational at leading climate research centers is tabulated in Table 2. The MM project supports its motivating hypothesis that the skill of seasonal prediction of ISMR cannot only approach old potential predictability estimates, but also raise that ceiling through estimating PPL with improved models. Specifically, within a span of 7 years, MM has brought the skill of ISMR prediction to 0.71 , which is above the older PPL estimate of 0.65. ISMR is much more potentially predictable, and that potential is achievable.

Beyond the aforementioned developmental activities of the MM, operationalization of a state-of-the-art dynamical seasonal prediction system $(\sim 38-\mathrm{km}$ atmospheric resolution), an extended-range prediction system for active and break spells $(\sim 110-\mathrm{km}$ atmospheric 
resolution), a high-resolution ensemble prediction system ( $\sim 33-\mathrm{km}$ resolution), and a very high-resolution deterministic prediction system $(\sim 12.5-\mathrm{km}$ resolution) for short- and medium-range weather took place together with the development of an ESM. Monsoon Mission was launched in the country at a time when the monsoon research community in India did not have access to significant HPC resources or dynamical models for research. Basic monsoon research was being carried out by various centers across India without proper coordination or focus. Therefore, a big challenge was to procure HPC resources and dynamical models to conduct research. The most important step was to identify the systematic biases in the model that are important at the different time scales in which we were interested. After the identification of systematic biases, the major challenge was to reduce them. Reduction in dry bias resulted from an increase in the atmospheric model resolution. However, this change resulted in slightly warm bias in tropical ocean basins. Similarly, changes to convection parameterization schemes resulted in an improvement in the mean monsoon rainfall but also resulted in a cold SST bias in tropical ocean basins. Therefore, the challenge has been to keep the systematic biases in ISMR simulation to a minimum. Another aspect of MM has been to improve the space-time characteristics of MISOs, as they are expected to provide twofold benefits of improving the skill of extended-range prediction as well as that of the seasonal prediction. Compared to the base version of the model, the various model development activities have shown improvements in space-time characteristics of MISOs and reduction in dry bias over land at various levels, vindicating our hypothesis. It was also important for the prediction system to be self-sufficient. Setting up an in-house data assimilation system was intended in this direction. Various parameterization schemes were developed using the observations collected in other regions of the globe. MM identified the importance of atmospheric and oceanic observational studies in Indian region to improve these parameterizations. Therefore, various observational programs were supported to understand physical processes. This success is only the beginning: there remains considerable scope for improving the predictions systems and India now has the talent and capabilities to be globally competitive in that quest. Therefore, continuous and dedicated work would be required to keep upgrading the prediction systems in the future.

This success required cooperation between operational entities and R\&D institutes within the MoES, as well as academic efforts from national and inter- national grant projects totaling hundreds of scientists and staff. These institutions with different primary mandates came together to work closely to achieve the objectives of MM.

Based on this success, MoES has launched the second phase of the MM in 2017, with a focus on predicting extreme weather and climate and advancing applications.

ACKNOWLEDGMENTS. Government of India, Ministry of Earth Sciences, supported this mission by providing generous funds by recognizing the need to improve monsoon prediction over India at different time scales. Beyond the list of authors of this article, a large number of individuals contributed enormously to the success of the Program by staying behind the scenes. We sincerely record our thanks to all of them here. We acknowledge Late Shri. D. R. Sikka for his immense support and guidance in the implementation of Monsoon Mission (MM). The continuous support received from The Monsoon Desk at NOAA's National Centers for Environmental Prediction (NCEP) is highly appreciated. The support received from the Center for Ocean-Land-Atmosphere Studies at the inception stage of MM for setting up the model is duly acknowledged. Monsoon Mission Directorate at IITM has provided the required administrative support for execution of MM. The contribution of all principal investigators (PIs), coPIs, and their staff associated with various MM projects is acknowledged. The manuscript has immensely benefitted from the critical comments by three anonymous reviewers and from the edits by Prof. Brian Mapes, BAMS Editor. We record our sincere thanks to all of them.

\section{REFERENCES}

Abhik, S., M. Halder, P. Mukhopadhyay, X. Jiang, and B. N. Goswami, 2013: A possible new mechanism for northward propagation of boreal summer intraseasonal oscillations based on TRMM and MERRA reanalysis. Climate Dyn., 40, 1611-1624, https://doi.org/10.1007/s00382-012-1425-x.

—, R. P. M. Krishna, M. Mahakur, M. Ganai, P. Mukhopadhyay, and J. Dudhia, 2017: Revised cloud processes to improve the mean and intraseasonal variability of Indian summer monsoon in climate forecast system: Part 1. J. Adv. Model. Earth Syst., 9, 1002-1029, https://doi.org/10.1002/2016MS000819.

Abhilash, S., A. K. Sahai, S. Pattnaik, and S. De, 2013: Predictability during active break phases of Indian summer monsoon in an ensemble prediction system using climate forecast system. J. Atmos. Sol.-Terr. Phys., 100-101, 13-23, https://doi.org/10.1016/j .jastp.2013.03.017. 
— - and Coauthors, 2014a: Prediction and monitoring of monsoon intraseasonal oscillations over Indian monsoon region in an ensemble prediction system using CFSv2. Climate Dyn., 42, 2801-2815, https:// doi.org/10.1007/s00382-013-2045-9.

—, A. K. Sahai, N. Borah, R. Chattopadhyay, S. Joseph, S. Sharmila, S. De, and B. N. Goswami, 2014b: Does bias correction in the forecasted SST improve the extended range prediction skill of active-break spells of Indian summer monsoon rainfall? Atmos. Sci. Lett., 15, 114-119, https://doi.org/10.1002/asl2.477.

— — - S. Pattnaik, B. N. Goswami, and A. Kumar, 2014c: Extended range prediction of active-break spells of Indian summer monsoon rainfall using an ensemble prediction system in NCEP Climate Forecast System. Int. J. Climatol., 34, 98-113, https://doi .org/10.1002/joc.3668.

— relationship and probabilistic prediction from the CFS-based grand ensemble prediction system. J. Appl. Meteor. Climatol., 54, 1569-1578, https://doi .org/10.1175/JAMC-D-14-0200.1.

_ , and Coauthors, 2015b: Better spread-error relationship in a multimodel ensemble prediction system. Bull. Amer. Meteor. Soc., 96, 1228-1229, https:// doi.org/10.1175/1520-0477-96.8.1221.

Alessandri, A., A. Borrelli, A. Cherchi, S. Materia, A. Navarra, J. Lee, and B. Wang, 2015: Prediction of Indian summer monsoon onset using dynamical subseasonal forecasts: Effects of realistic initialization of the atmosphere. Mon. Wea. Rev., 143, 778793, https://doi.org/10.1175/MWR-D-14-00187.1.

Annamalai, H., B. Taguchi, J. P. McCreary, M. Nagura, and T. Miyama, 2017: Systematic errors in South Asian monsoon simulation: Importance of equatorial Indian Ocean Processes. J. Climate, 30, 8159-8178, https://doi.org/10.1175/JCLI-D-16-0573.1.

Bhargava, K., E. Kalnay, J. A. Carton, and F. Yang, 2018: Estimation of systematic errors in the GFS using analysis increments. J. Geophys. Res. Atmos., 123, 1626-1637, https://doi.org/10.1002/2017JD027423.

Bhowmick, M., and D. J. Parker, 2018: Analytical solution to a thermodynamic model for the sensitivity of afternoon deep convective initiation to the surface Bowen ratio. Quart. J. Roy. Meteor. Soc., 144, 2216-2229, https://doi.org/10.1002/qj.3340.

Borah, N., A. K. Sahai, S. Abhilash, R. Chattopadhyay, S. Joseph, S. Sharmila, and A. Kumar, 2015: An assessment of real-time extended range forecast of 2013 Indian summer monsoon. Int. J. Climatol., 35, 2860-2876, https://doi.org/10.1002/joc.4178.

Chattopadhyay, N., K. V. Rao, A. K. Sahai, R. Balasubramanian, D. S. Pai, D. R. Pattanaik, S. V.
Chandras, and S. Khedikar, 2018: Usability of extended range and seasonal weather forecast in Indian agriculture. Mausam, 69 (1), 29-44.

Chattopadhyay, R., S. A. Rao, C. T. Sabeerali, G. George, D. N. Rao, A. Dhakate, and K. Salunke, 2016: Large scale teleconnection patterns of Indian summer monsoon as revealed by CFSv2 retrospective seasonal forecast runs. Int. J. Climatol. , 36, 3297-3313, https:// doi.org/10.1002/JOC.4556.

—, R. P. M. Krishna, S. Joseph, A. Dey, R. Mandal, and A. K. Sahai, 2018: A comparison of extendedrange prediction of monsoon in the IITM-CFSv2 with ECMWF S2S Forecast System. IITM Research Rep. RR-139, 36 pp., www.tropmet.res.in/ lip /Publication/RR-pdf/RR-139.pdf.

De, S., A. Hazra, and H. S. Chaudhari, 2016: Does the modification in critical relative humidity of NCEP CFSv2 dictate Indian mean summer monsoon forecast?: Evaluation through thermodynamical and dynamical aspects. Climate Dyn., 46, 1197-122, https://doi.org/10.1007/s00382-015-2640-z.

DelSole, T., and J. Shukla, 2009: Artificial skill due to predictor screening. J. Climate, 22, 331-345, https:// doi.org/10.1175/2008JCLI2414.1.

Drbohlav, H.-K. L., and V. Krishnamurthy, 2010: Spatial structure, forecast errors and predictability of South Asian monsoon in CFS monthly retrospective forecasts. J. Climate, 23, 4750-4769, https://doi .org/10.1175/2010JCLI2356.1.

Durai, V. R., and S. K. R. Bhowmik, 2014: Prediction of Indian summer monsoon in short to medium range time scale with high resolution Global Forecast System (GFS) T574 and T382. Climate Dyn., 42, 15271551, https://doi.org/10.1007/s00382-013-1895-5.

Ek, M. B., K. E. Mitchell, Y. Lin, E. Rogers, P. Grunmann, V. Koren, G. Gayno, and J. D. Tarpley, 2003: Implementation of Noah land surface model advances in the National Centers for Environmental Prediction operational mesoscale Eta model. J. Geophys. Res., 108, 8851, https://doi.org/10.1029/2002JD003296.

Fitzpatrick, R. G. J., D. J. Parker, and P. D. Willetts, 2016: Assessing the level of spatial homogeneity of the agronomic Indian monsoon onset. Geophys. Res. Lett., 43, 11 867-11 874, https://doi.org/10.1002/2016GL070711.

Fletcher, J. K., and Coauthors, 2019: The dynamic and thermodynamic structure of the monsoon over southern India: New observations from the INCOMPASS IOP. Quart. J. Roy. Meteor. Soc., https:// doi.org/10.1002/QJ.3439, in press.

Gadgil, S., and S. Gadgil, 2006: The Indian monsoon, GDP and agriculture. Econ. Polit. Wkly., 41 (47), 4887-4895.

_ , and J. Srinivasan, 2013: Monsoon prediction: Hits, misses and false alarms. Curr. Sci., 104 (8), 1005. 
_- M. Rajeevan, and R. Nanjundiah, 2005: Monsoon prediction - Why yet another failure? Curr. Sci., 88, 1389-1400.

Ganai, M., P. Mukhopadhyay, R. P. M. Krishna, and M. Mahakur, 2015: The impact of revised simplified Arakawa-Schubert convection parameterization scheme in CFSv2 on the simulation of the Indian summer monsoon. Climate Dyn., 45, 881-902, https://doi.org/10.1007/s00382-014-2320-4.

—, R. P. M. Krishna, P. Mukhopadhyay, and M. Mahakur, 2016: The impact of revised simplified Arakawa-Schubert scheme on the simulation of mean and diurnal variability associated with active and break phases of Indian summer monsoon using CFSv2. J. Geophys. Res. Atmos., 121, 11 038-11 054, https://doi.org/10.1002/2016JD025393.

—, P. Mukhopadhyay, R. P. M. Krishna, S. Abhik, and M. Halder, 2019: Revised cloud and convective parameterization in CFSv2 improve the underlying processes for northward propagation of Intraseasonal oscillations as proposed by the observationbased study. Climate Dyn., 53, 2793-2805, https:// doi.org/10.1007/S00382-019-04657-9.

George, G., D. N. Rao, C. T. Sabeerali, A. Srivastava, and S. A. Rao, 2016: Indian summer monsoon prediction and simulation in CFSv2 coupled model. Atmos. Sci. Lett., 17, 57-64, https://doi.org/10.1002 /ASL.599.

—, C. Sarangi, S. N. Tripathi, T. Chakraborty, and A. Turner, 2018: Vertical structure and radiative forcing of monsoon clouds over Kanpur during the 2016 INCOMPASS field campaign. J. Geophys. Res. Atmos., 123, 2152-2174, https://doi .org/10.1002/2017JD027759.

Goswami, B. B., R. P. Krishna, P. Mukhopadhyay, M. Khairoutdinov, and B. N. Goswami, 2015: Simulation of the Indian summer monsoon in the superparameterized Climate Forecast System version 2: Preliminary results. J. Climate, 28, 8988-9012, https://doi .org/10.1175/JCLI-D-14-00607.1.

- B. Khouider, R. Phani, P. Mukhopadhyay, and A. J. Majda, 2017a: Improved tropical modes of variability in the NCEP Climate Forecast System (version 2) via a stochastic multicloud model. J. Atmos. Sci., 74, 3339-3366, https://doi.org/10.1175/JAS-D-17 -0113.1 .

,,,---- , and,$- 2017 \mathrm{~b}$ : Improving synoptic and intraseasonal variability in CFSv2 via stochastic representation of organized convection. Geophys. Res. Lett., 44, 1104-1113, https://doi .org/10.1002/2016GL071542.

,,,---- , and,$- 2017 \mathrm{c}$ : Implementation and calibration of a stochastic multicloud convective parameterization in the NCEP Climate Forecast System (CFSv2). J. Adv. Model. Earth Syst., 9, 1721-1739, https://doi.org/10.1002/2017MS001014.

Goswami, B. N., G. Wu, T. Yasunari, B. N. Goswami, G. Wu, and T. Yasunari, 2006: The annual cycle, intraseasonal oscillations, and roadblock to seasonal predictability of the Asian summer monsoon. J. Climate, 19, 5078-5099, https://doi.org/10.1175 /JCLI3901.1.

— M. C. Wheeler, J. C. Gottschalck, and D. E. Waliser, 2011: Intraseasonal variability and forecasting: A review of recent research. The Global Monsoon System: Research and Forecast, 2nd ed. C.-P. Chang et al., Eds., World Scientific Series on Asia-Pacific Weather and Climate, Vol. 5, World Scientific, 389-407.

Griffies, S. M., M. J. Harrison, R. C. Pacanowski, and A. Rosati, 2004: A technical guide to MOM4. GFDL Ocean Group Tech. Rep. 5, NOAA/GFDL, 342 pp., www.gfdl.noaa.gov/bibliography/related _files/smg0301.pdf.

Han, J., and H. L. Pan, 2011: Revision of convection and vertical diffusion schemes in the NCEP global forecast system. Wea. Forecasting, 26, 520-533, https:// doi.org/10.1175/WAF-D-10-05038.1.

Hazra, A., H. S. Chaudhari, S. K. Saha, S. Pokhrel, and B. N. Goswami, 2017: Progress towards achieving the challenge of Indian Summer monsoon climate simulation in a coupled ocean-atmosphere model. J. Adv. Model. Earth Syst., 9, 2268-2290, https://doi .org/10.1002/2017MS000966.

Hong, S.-Y., and J.-O. J. Lim, 2006: The WRF singlemoment 6-class microphysics scheme (WSM6). J. Korean Meteor. Soc., 42, 129-151.

Huffman, G. J., R. F. Adler, M. M. Morrissey, D. T. Bolvin, S. Curtis, R. Joyce, B. McGavock, and J. Susskind, 2001: Global precipitation at one-degree daily resolution from multisatellite observations. $J$. Hydrometeor., 2, 36-50, https://doi.org/10.1175/1525 -7541(2001)002<0036:GPAODD>2.0.CO;2.

Hunt, K. M. R., and A. G. Turner, 2017a: The effect of soil moisture perturbations on Indian monsoon depressions in a numerical weather prediction model. Quart. J. Roy. Meteor. Soc., 143, 1756-1771, https:// doi.org/10.1002/qj.3030.

- , and — 2017b: The effect of horizontal resolution on Indian monsoon depressions in the Met Office NWP model. Quart. J. Roy. Meteor. Soc., 143, 1756-1771, https://doi.org/10.1002/qj.3030.

- _ - P. M. Inness, D. E. Parker, and R. C. Levine, 2016: On the structure and dynamics of Indian monsoon depressions. Mon. Wea. Rev., 144, 3391-3416, https://doi.org/10.1175/MWR-D-15-0138.1. 
Jiang, X., D. E. Waliser, J. L. Li, and C. Woods, 2011: Vertical cloud structures of the boreal summer intraseasonal variability based on CloudSat observations and ERA-interim reanalysis. Climate Dyn., 36, 2219-2232, https://doi.org/10.1007/s00382-010 -0853-8.

Johnson, S. J., A. Turner, S. Woolnough, G. Martin, and C. MacLachlan, 2017: An assessment of Indian monsoon seasonal forecasts and mechanisms underlying monsoon interannual variability in the Met Office GloSea5-GC2 system. Climate Dyn., 48, 1447-1465, https://doi.org/10.1007/s00382-016-3151-2.

Joseph, S., and Coauthors, 2015a: North Indian heavy rainfall event during June 2013: Diagnostics and extended range prediction. Climate Dyn., 44, 20492065, https://doi.org/10.1007/s00382-014-2291-5.

—, A. K. Sahai, S. Abhilash, R. Chattopadhyay, N. Borah, B. E. Mapes, M. Rajeevan, and A. Kumar, 2015b: Development and evaluation of an objective criterion for the real-time prediction of Indian summer monsoon onset in a coupled model framework. J. Climate, 28, 6234-6248, https://doi.org/10.1175 /JCLI-D-14-00842.1.

— , and Coauthors, 2016: Extremes in June rainfall during the Indian summer monsoons of 2013 and 2014: observational analysis and extended-range prediction. Quart. J. Roy. Meteor. Soc., 142, 1276-1289, https://doi.org/10.1002/qj.2730.

—, A. K. Sahai, R. Phani, R. Mandal, A. Dey and R. Chattopadhyay, 2017: Evaluation of extended range forecast skill on subdivisional scale over India. IITM Research Rep. RR-137, 38 pp., www.tropmet.res .in/ lip/Publication/RR-pdf/RR-137.pdf.

—, R. Mandal, A. K. Sahai, R. Phani, A. Dey and R. Chattopadhyay, 2018: Diagnostics and real-time extended range prediction of heat waves over India. IITM Research Rep. RR-141, 33 pp., www.tropmet .res.in/ lip/Publication/RR-pdf/RR-141.pdf.

Kang, I.-S., and J. Shukla, 2006: Dynamic seasonal prediction and predictability of the monsoon. The Asian Monsoon, B. Wang, Ed., Springer, 585-612.

Khouider, B., J. Biello, and A. J. Majda, 2010: A stochastic multicloud model for tropical convection. Commun. Math. Sci., 8, 187-216, https://doi.org/10.4310/CMS .2010.v8.n1.a10.

Kim, H.-M., P. J. Webster, J. A. Curry, and V. E. Toma, 2012: Asian summer monsoon prediction in ECMWF System 4 and NCEP CFSv2 retrospective seasonal forecasts. Climate Dyn., 39, 2975-2991, https://doi.org/10.1007/s00382-012-1470-5.

Konwar, M., R. S. Maheskumar, J. R. Kulkarni, E. Freud, B. N. Goswami, and D. Rosenfeld, 2012: Aerosol control on depth of warm rain in convective clouds. J. Geophys. Res., 117, D13204, https://doi .org/10.1029/2012JD017585.

Krishna, R. P. M., S. A. Rao, A. Srivastava, H. P. Kottu, M. Pradhan, P. Pillai, R. A. Dandi, and C. T. Sabeerali, 2019: Impact of convective parameterization on the seasonal prediction skill of Indian summer monsoon. Climate Dyn., 53, 6227-6243, https://doi.org/10.1007 /s00382-019-04921-y.

Krishnamurthy, V., and B. N. Goswami, 2000: Indian monsoon-ENSO relationship on interdecadal timescale. J. Climate, 13, 579-595, https://doi .org/10.1175/1520-0442(2000)013<0579:IMEROI $>2.0 . \mathrm{CO} ; 2$.

Krishnan, R., and Coauthors, 2019: The IITM Earth System Model (ESM): Development and Future Roadmap. Current Trends in the Representation of Physical Processes in Weather and Climate Models, D. A. Randall et al., Eds., Springer, 183-195.

Kulkarni, J. R., and Coauthors, 2012: The Cloud Aerosol Interaction and Precipitation Enhancement Experiment (CAIPEEX): Overview and preliminary results. Curr. Sci., 102, 413-425.

Kumar, K. K., B. Rajagopalan, and M. A. Cane, 1999: On the weakening relationship between the Indian Monsoon and ENSO. Science, 284, $2156-$ 2159, https://doi.org/10.1126/SCIENCE.284.5423 .2156 .

—, M. Hoerling, and B. Rajagopalan, 2005: Advancing dynamical prediction of Indian monsoon rainfall. Geophys. Res. Lett., 32, L08704, https://doi .org/10.1029/2004GL021979.

Kumar, P., M. Khare, R. M. Harrison, W. J. Bloss, A. C. Lewis, H. Coe, and L. Morawska, 2015: New directions: Air pollution challenges for developing megacities like Delhi. Atmos. Environ., 122, 657-661, https://doi.org/10.1016/j.atmosenv.2015.10.032.

Kumar, S., A. Arora, R. Chattopadhyay, A. Hazra, S. A. Rao, and B. N. Goswami, 2017: Seminal role of stratiform clouds in large-scale aggregation of tropical rain in boreal summer monsoon intraseasonal oscillations. Climate Dyn., 48, 999-1015, https://doi .org/10.1007/s00382-016-3124-5.

Mandal, V., U. K. De, B. K. Basu, V. Mandal, U. K. De, and B. K. Basu, 2007: Precipitation forecast verification of the Indian summer monsoon with intercomparison of three diverse regions. Wea. Forecasting, 22, 428-443, https://doi.org/10.1175/WAF1010.1.

Martin, G. M., S. F. Milton, C. A. Senior, M. E. Brooks, S. Ineson, T. Reichler, and J. Kim, 2010: Analysis and reduction of systematic errors through a seamless approach to modeling weather and climate. J. Climate, 23, 5933-5957, https://doi .org/10.1175/2010JCLI3541.1. 
Mishra, S. K., S. Sahany, P. Salunke, I.-S. Kang, and S. Jain, 2018: Fidelity of CMIP5 multi-model mean in assessing Indian monsoon simulations. njp Climate Atmos. Sci., 1, 39, https://doi.org/10.1038/S41612 -018-0049-1.

Mitra, A. K., I. M. Momin, E. N. Rajagopal, S. Basu, M. N. Rajeevan, and T. N. Krishnamurthi, 2013: Gridded daily Indian monsoon rainfall for 14 seasons: Merged TRMM and IMD gauge analyzed values. J. Earth Syst. Sci., 122, 1173-1182, https://doi .org/10.1007/s12040-013-0338-3.

Pai, D. S., S. A. Rao, S. Senroy, M. Pradhan, P. A. Pillai, and M. Rajeevan, 2017: Performance of the operational and experimental long-range forecasts for the 2015 southwest monsoon rainfall. Curr. Sci., 112, 68-75, https://doi.org/10.18520/cs/v112/i01/68-75.

Palmer, T. N., and D. L. T. Anderson, 1994: The prospects for seasonal forecasting-A review paper. Quart. J. Roy. Meteor. Soc., 120, 755-793, https://doi .org/10.1002/QJ.49712051802.

Peatman, S. C., and N. P. Klingaman, 2018: The Indian summer monsoon in MetUM-GOML2.0: Effects of air-sea coupling and resolution. Geosci. Model Dev., 11, 4693-4709, https://doi.org/10.5194/gmd -11-4693-2018.

Phani, R., and Coauthors, 2016: Improvement of cloud and convective Parameterizations in Climate Forecast System Version 2 (CFSv2): Indian Summer Monsoon perspective. IITM Research Rep. RR-135, 95 pp., www.tropmet.res.in/ lip/Publication/RR -pdf/RR-135.pdf.

Pillai, P. A., S. A. Rao, G. George, D. N. Rao, S. Mahapatra, M. Rajeevan, A. Dhakate, and K. Salunke, 2017: How distinct are the two flavors of El Niño in retrospective forecasts of Climate Forecast System version 2 (CFSv2)? Climate Dyn., 48, 3829-3854, https://doi.org/10.1007/s00382-016-3305-2.

Pokhrel, S., A. Hazra, H. S. Chaudhari, S. K. Saha, F. Paulose, S. Krishna, P. M. Krishna, and S. A. Rao, 2018: Hindcast skill improvement in Climate Forecast System (CFSv2) using modified cloud scheme. Int. J. Climatol., 38, 2994-3012, https://doi .org/10.1002/JOC.5478.

Prasad, V. S., and C. J. Johny, 2016: Impact of hybrid GSI analysis using ETR ensembles. J. Earth Syst. Sci., 125, 521-538, https://doi.org/10.1007/s12040-016 $-0673-2$.

- - — , and J. S. Sodhi, 2016: Impact of 3D Var GSI-ENKF hybrid data assimilation system. J. Earth Syst. Sci., 125, 1509-1521, https://doi.org/10.1007 /s12040-016-0761-3.

Preethi, B., R. H. Kripalani, and K. Krishna Kumar, 2010: Indian summer monsoon rainfall variability in global coupled ocean-atmospheric models. Climate Dyn., 35, 1521-1539, https://doi.org/10.1007/s00382 -009-0657-x.

Rai, S., and V. Krishnamurthy, 2011: Error growth in Climate Forecast System daily retrospective forecasts of South Asian monsoon. J. Geophys. Res., 116, D03108, https://doi.org/10.1029/2010JD014840.

Rajeevan, M., 2001: Prediction of Indian summer monsoon: Status, problems and prospects. Curr. Sci., 81 (11), 1451-1458.

—, J. Bhate, J. D. Kale, and B. Lal, 2006: High resolution daily gridded rainfall data for the Indian region: Analysis of break and active. Curr. Sci., 91, 296-306. _ D. S. Pai, R. Anil Kumar, and B. Lal, 2007: New statistical models for long-range forecasting of southwest monsoon rainfall over India. Climate Dyn., 28, 813-828, https://doi.org/10.1007/s00382-006 -0197-6.

— , S. Gadgil, and J. Bhate, 2010: Active and break spells of the Indian summer monsoon. J. Earth Syst. Sci., 119, 229-247, https://doi.org/10.1007/s12040 -010-0019-4.

—, C. K. Unnikrishnan, and B. Preethi, 2012: Evaluation of the ENSEMBLES multi-model seasonal forecasts of Indian summer monsoon variability. Climate Dyn., 38, 2257-2274, https://doi.org/10.1007 /s00382-011-1061-x.

Ramesh, K. V., and P. Goswami, 2015: Assessing reliability of regional climate projections: the case of Indian monsoon. Sci. Rep., 4, 4071, https://doi.org/10.1038 /srep04071.

Ramu, D. A., and Coauthors, 2016: Indian summer monsoon rainfall simulation and prediction skill in the CFSv2 coupled model: Impact of atmospheric horizontal resolution. J. Geophys. Res. Atmos., 121, 2205- 2221, https://doi.org/10.1002/2015JD024629.

— , and Coauthors, 2017: Prediction of seasonal summer monsoon rainfall over homogenous regions of India using dynamical prediction system. J. Hydrol., 546, 103-112, https://doi.org/10.1016/j .jhydrol.2017.01.010.

Rao, S. A., and Coauthors, 2011: Modulation of SST, SSS over northern Bay of Bengal on ISO time scale. J. Geophys. Res., 116, C09026, https://doi .org/10.1029/2010JC006804.

Ravichandran, M., D. Behringer, S. Sivareddy, M. S. Girishkumar, N. Chacko, and R. Harikumar, 2013: Evaluation of the Global Ocean Data Assimilation System at INCOIS: The tropical Indian Ocean. Ocean Modell., 69, 123-135, https://doi.org/10.1016/j .ocemod.2013.05.003.

Sabeerali, C. T., R. A. Dandi, A. Dhakate, K. Salunke, S. Mahapatra, and S. A. Rao, 2013: Simulation of 
boreal summer intraseasonal oscillations in the latest CMIP5 coupled GCMs. J. Geophys. Res. Atmos., 118, 4401-4420, https://doi.org/10.1002/JGRD.50403.

Saha, S. K., S. Pokhrel, and H. S. Chaudhari, 2013: Influence of Eurasian snow on Indian summer monsoon in NCEP CFSv2 freerun. Climate Dyn., 41, 1801-1815, https://doi.org/10.1007/s00382-012-1617-4.

- - and Coauthors, 2014: The NCEP Climate Forecast System version 2. J. Climate, 27, 2185-2208, https:// doi.org/10.1175/JCLI-D-12-00823.1.

- , K. Sujith, S. Pokhrel, H. S. Chaudhari, and A. Hazra, 2017: Effects of multilayer snow scheme on the simulation of snow: Offline Noah and coupled with NCEPCFSv2. J. Adv. Model. Earth Syst., 9, 271-290, https://doi.org/10.1002/2016MS000845.

—, A. Hazra, S. Pokhrel, H. S. Chaudhari, K. Sujith, A. Rai, H. Rahaman, and B. N. Goswami, 2019: Unraveling the mystery of Indian summer monsoon prediction: Improved estimate of predictability limit. J. Geophys. Res. Atmos., 124, 1962-1974, https://doi .org/10.1029/2018JD030082.

Sahai, A. K., and Coauthors, 2013: Simulation and Extended range prediction of monsoon intraseasonal oscillations in NCEP CFS/GFS version 2 framework. Curr. Sci., 104, 1394-1408.

—, S. Abhilash, R. Chattopadhyay, N. Borah, S. Joseph, S. Sharmila, and M. Rajeevan, 2015a: Highresolution operational monsoon forecasts: An objective assessment. Climate Dyn., 44, 3129-3140, https:// doi.org/10.1007/s00382-014-2210-9.

_-, R. Chattopadhyay, S. Joseph, R. Mandal, A. Dey, S. Abhilash, R. P. M. Krishna, and N. Borah, 2015b: Real-time performance of a multi-model ensemblebased extended range forecast system in predicting the 2014 monsoon season based on NCEP-CFSv2. Curr. Sci., 109 (10), 1802-1813.

—, R. Chattopadhyay, S. Joseph, R. Phani, and S. Abhilash, 2016: Extended range prediction system and its application. Vayu Mandal, 42, 75-96.

_- and Coauthors, 2017: Potential predictability of wet/dry spells transitions during extreme monsoon years: Optimism for dynamical extended range prediction. Nat. Hazards, 88, 853-865, https://doi .org/10.1007/s11069-017-2895-2.

_, R. Chattopadhyay, S. Joseph, P. M. Krishna, D. R. Pattnaik, and S. Abhilash, 2019: Seamless prediction of monsoon onset and active/break phases. SubSeasonal to Seasonal Prediction: The Gap Between Weather and Climate Forecasting, A. Robertson and F. Vitart, Eds., Elsevier, 421-438, https://doi .org/10.1016/B978-0-12-811714-9.00020-6.

Sanchez-Franks, A., E. C. Kent, A. J. Matthews, B. G. Webber, S. C. Peatman, and P. N. Vinayachandran,
2018: Intraseasonal variability of air-sea fluxes over the Bay of Bengal during the southwest monsoon. J. Climate, 31, 7087-7109, https://doi.org/10.1175 /JCLI-D-17-0652.1.

Saranya Ganesh, S., A. K. Sahai, S. Abhilash, S. Joseph, A. Dey, R. Mandal, R. Chattopadhyay, and R. Phani, 2018: A new approach to improve the track prediction of tropical cyclones over north Indian Ocean. Geophys. Res. Lett., 45, 7781-7789, https:// doi.org/10.1029/2018GL077650.

Shah, R., A. K. Sahai, and V. Mishra, 2017: Short to sub-seasonal hydrologic forecast to manage water and agricultural resources in India. Hydrol. Earth Syst. Sci., 21, 707-720, https://doi.org/10.5194/hess -21-707-2017.

Sharmila, S., P. A. Pillai, S. Joseph, M. Roxy, R. P. M. Krishna, R. Chattopadhyay, S. Abhilash, and B. N. Goswami, 2013: Role of ocean-atmosphere interaction on northward propagation of Indian summer monsoon intra-seasonal oscillations (MISO). Climate Dyn., 41, 1651-1669, https://doi.org/10.1007/s00382 -013-1854-1.

Shashikanth, K., K. Salvi, S. Ghosh, and K. Rajendran, 2014: Do CMIP5 simulations of Indian summer monsoon rainfall differ from those of CMIP3? Atmos. Sci. Lett., 15, 79-85, https://doi.org/10.1002/asl2.466.

Shenoi, S. S. C., D. Shankar, and S. R. Shetye, 2002: Differences in heat budgets of the near-surface Arabian Sea and Bay of Bengal. J. Geophys. Res., 107, 3052, https://doi.org/10.1029/2000JC000679.

Shukla, J., and D. A. Paolino, 1983: The southern oscillation and long-range forecasting of the summer monsoon rainfall over India. Mon. Wea. Rev., 111, 1830-1837, https://doi.org/10.1175/1520 -0493(1983)111<1830:TSOALR>2.0.CO;2.

Sluka, T. C., 2018: Strongly coupled ocean-atmosphere data assimilation with the local ensemble transform Kalman filter. Ph.D dissertation, University of Maryland, 152 pp., https://doi.org/10.13016/vez0-ikjn. — , S. G. Penny, E. Kalnay, and T. Miyoshi, 2016: Assimilating atmospheric observations into the ocean using strongly coupled ensemble data assimilation. Geophys. Res. Lett., 43, 752-759, https://doi .org/10.1002/2015GL067238.

Sperber, K. R., H. Annamalai, I.-S. Kang, A. Kitoh, A. Moise, A. Turner, B. Wang, and T. Zhou, 2013: The Asian summer monsoon: An intercomparison of CMIP5 vs. CMIP3 simulations of the late 20th century. Climate Dyn., 41, 2711-2744, https://doi .org/10.1007/s00382-012-1607-6.

Sree Lekha, J., J. M. Buckley, A. Tandon, and D. Sengupta, 2018: Subseasonal dispersal of freshwater in the northern Bay of Bengal in the 2013 summer 
monsoon season. J. Geophys. Res. Oceans, 123, 6330-6348, https://doi.org/10.1029/2018JC014181.

Srivastava, A., M. Pradhan, G. George, A. Dhakate, K. Salunke, and S. A. Rao, 2015: Long range forecast of the Indian summer monsoon using Climate Forecast System. A research report on the 2015 southwest monsoon, M. Mujumdar, C. Gnanaseelan, and M. Rajeevan, Eds., IITM Research Rep. RR-185, Indian Institute of Tropical Meteorology, 58-62, www. tropmet.res.in/ lip/Publication/RR-pdf/RR-185.pdf.

Swapna, P., and Coauthors, 2015: The IITM Earth System Model: Transformation of a seasonal prediction model to a long-term climate model. Bull. Amer. Meteor. Soc., 96, 1351-1367, https://doi.org/10.1175 /BAMS-D-13-00276.1.

—, R. Krishnan, N. Sandeep, A. G. Prajeesh, D. C. Ayantika, S. Manmeet, and R. Vellore, 2018: Longterm climate simulations using the IITM Earth System Model (IITM-ESMv2) with focus on the South Asian monsoon. J. Adv. Model. Earth Syst., 10, 1127-1149, https://doi.org/10.1029/2017MS001262.

Tang, W., and Coauthors, 2017: Validating SMAP SSS with in situ measurements. Remote Sens. Environ., 200, 326-340, https://doi.org/10.1016/j .rse.2017.08.021.

Vinayachandran, P. N., V. S. N. Murty, and V. R. Babu, 2002: Observations of barrier layer formation in the Bay of Bengal during summer monsoon. J. Geophys. Res., 107, 8018, https://doi.org/10.1029/2001JC000831.

— , and Coauthors, 2018: BoBBLE: Ocean-atmosphere interaction and its impact on the South Asian monsoon. Bull. Amer. Meteor. Soc., 99, 1569-1587, https:// doi.org/10.1175/BAMS-D-16-0230.1.

Walker, G. T., 1925: Correlation in seasonal variations of weather-A further study of world weather. Mon. Wea. Rev., 53, 252-254, https://doi.org/10.1175/1520 -0493(1925)53<252:CISVOW>2.0.CO;2.
Wang, B., Q. Ding, X. Fu, I. Kang, K. Jin, J. Shukla, and F. Doblas-Reyes, 2005: Fundamental challenge in simulation and prediction of summer monsoon rainfall. Geophys. Res. Lett., 32, L15711, https:/doi .org/10.1029/2005GL022734.

—, B. Xiang, J. Li, P. J. Webster, M. N. Rajeevan, J. Liu, and K.-J. Ha, 2015: Rethinking Indian monsoon rainfall prediction in the context of recent global warming. Nat. Commun., 6, 7154, https://doi .org/10.1038/ncomms8154.

Webber, B. G. M., A. J. Matthews, P. N. Vinayachandran, C. P. Neema, A. Sanchez-Franks, V. Vijith, P. Amol, and D. B. Baranowski, 2018: The dynamics of the Southwest Monsoon Current in 2016 from highresolution in situ observations and models. J. Phys. Oceanogr., 48, 2259-2282, https://doi.org/10.1175 /JPO-D-17-0215.1.

Webster, P. J., V. O. Magaña, T. N. Palmer, J. Shukla, R. A. Tomas, M. Yanai, and T. Yasunari, 1998: Monsoons: Processes, predictability, and the prospects for prediction. J. Geophys. Res., 103, 14451-14510, https:// doi.org/10.1029/97JC02719.

Willetts, P. D., and Coauthors, 2017: The 2015 Indian summer monsoon onset-Phenomena, forecasting and research flight planning. Weather, 72, 168-175, https://doi.org/10.1002/wea.2819.

Winton, M., 2000: A reformulated three-layer sea ice model. J. Atmos. Oceanic Technol., 17, 525-531, https:// doi.org/10.1175/1520-0426(2000)017<0525:ARTLSI $>2.0 . \mathrm{CO} ; 2$.

Xavier, P. K., and B. N. Goswami, 2007: A promising alternative to prediction of seasonal mean all India rainfall. Curr. Sci., 93, 195-202.

Zhao, Q., and F. H. Carr, 1997: A prognostic cloud scheme for operational NWP models. Mon. Wea. Rev., 125, 1931-1953, https://doi.org/10.1175/1520 -0493(1997)125<1931:APCSFO>2.0.CO;2. 